Biosensors and Bioelectronics, Volume 20, Issue 12, 20th Anniversary of Biosensors and Bioelectronics, 15 June 2005, Pages 2435-2453

\title{
Home Blood Glucose Biosensors: A Commercial Perspective
}

\author{
Jeffrey D. Newman \& Anthony P.F. Turner \\ Cranfield University, Silsoe, Bedfordshire MK45 4DT, UK \\ www.silsoe.cranfield.ac.uk
}

\begin{abstract}
Twenty years on from a review in the first issue of this journal, this contribution revisits glucose sensing for diabetes with an emphasis on commercial developments in the home blood glucose testing market. Following a brief introduction to the needs of people with diabetes, the review considers defining technologies that have enabled the introduction of commercial products and then reviews the products themselves. Drawing heavily on the performance of actual instruments and publically available information from the companies themselves, this work is designed to complement more conventional reviews based on papers published in scholarly journals. It focuses on the commercial reality today and the products that we are likely to see in the near future.
\end{abstract}

\section{Keywords}

Blood glucose monitors, diabetes, glucose biosensors, alternate-site testing, lancing, Medisense

\section{Introduction}

Despite the many technological advances in biosensor research and development and the introduction of many different products, glucose biosensors still account for approximately $85 \%$ of the current world market for biosensors, which has recently been estimated to be around $\$ 5$ billion (Newman et al., 2004). The reasons why the glucose market was particularly receptive to the introduction of biosensors are numerous, but the single greatest factor was the prevalence of diabetes in developed nations.

\subsection{Diabetes}

Diabetes is a metabolic disorder, in which the pancreas underproduces or does not produce insulin. Because cells need insulin to absorb blood sugar (glucose) for their energy needs, the cells of people with diabetes suffer from a shortage of glucose, while glucose levels build up in the blood. The disease is a major world health problem. It is estimated that there are over 170 million diabetics worldwide (WHO, 2004). Worse still, incidence of the disease has risen by an alarming $11 \%$ over the last five years, and a further doubling of new cases is predicted in the next 25 years (Table 
1). Increasing obesity, a more sedentary lifestyle and the spread of western eating habits (high fat, salt and sugar content) are believed to be the major causes of this.

Table 1: The Growing Global Problem of Diabetes

\begin{tabular}{|l|c|c|c|}
\hline \multicolumn{1}{|c|}{ Statistics } & 1995 & 2000 (estimate) & 2025 (estimate) \\
\hline $\begin{array}{l}\text { People with Diabetes } \\
\text { (million) }\end{array}$ & 135 & 154 & 300 \\
\% in Developed Countries & 25.2 & 23.8 & 17.1 \\
Female/Male Ratio & 1.18 & 1.16 & 1.12 \\
\hline \multicolumn{4}{|c|}{ Source: World Health Organisation }
\end{tabular}

There are three types of diabetes:

Type 1 diabetes usually affects the young and occurs when the pancreas no longer produces any (or very little) insulin. Approximately $10 \%$ of diabetics have Type 1.

Type 2 diabetes commonly affects middle-aged or older patients and occurs when the pancreas does not produce enough insulin or when the body does not use the insulin that is produced effectively. $90 \%$ of people with diabetes have Type 2 .

Gestational diabetes is a temporary condition that occurs during pregnancy. It affects two to four $\%$ of all pregnancies with an increased risk of developing diabetes for both mother and child.

Diabetes is one of the leading causes of death by disease. When left untreated or improperly managed, the high levels of blood sugar associated with diabetes can slowly damage both the small and large blood vessels in the body, resulting in a variety of complications (American Diabetes Association, 2004), including:

- Incidence of heart disease is raised between two and four-fold on average

- The condition is a leading cause of adult blindness

- Diabetes is responsible for over $40 \%$ of all new cases of serious kidney disease

- Over $60 \%$ of all non-traumatic limb amputations are due to diabetes

- Diabetes is a major cause of erectile dysfunction.

With careful management, these complications can be delayed and even prevented. For many patients, this involves the regular measurement of blood glucose levels. The American Diabetes Association's Consensus Statement on Self-Monitoring of Blood Glucose recommends that people with Type 1 diabetes in intensive therapy should test at least four times a day (American Diabetes Association, 1994). Even people with Type 2 in good control are encouraged to check twice a day. Nevertheless, it appears that frequency of testing is reaching a plateau, or even declining in many countries. This trend is puzzling when one considers the medical benefits of glucose monitoring. 
It is widely agreed that frequent self monitoring is an essential and central part of controlling diabetes. This provides data to:

- Identify trends in glucose control

- Identify factors that may cause high or low glucose values

- Evaluate the impact of activity, diet and medication

- Optimise or change a treatment plan

- Decide what needs to be done when the patient is ill

It is also possible to relate the patient's general feeling of health to their diabetic condition and, perhaps, alert them to things that may be unconnected to the illness.

This debate is not straightforward, however. One factor that is often overlooked is that the numbers obtained by testing are only one part of the picture, which requires additional data to be complete. For example, it is important to relate the number to what and when the patient last ate. The patient's exercise regime must also be considered, as well as when and how much medication has been taken. If this were not complicated enough, the patient (and physician) need to consider factors such as whether the patient has recently been ill, or even subjected to high levels of stress, which can distort the picture.

For many years it has been assumed that the pain associated with frequent self-testing was the reason why tests were not carried out as often as recommended. There may be some truth in this, but it is clearly not as important a factor as was first thought. The introduction of smaller lancets and alternate site testing has not increased testing frequency. In fact, as was mentioned above, the opposite seems to be happening.

One problem is that many patients do not understand what their results mean. For non-insulin dependent diabetics, where there is often no direct action step, there appears little incentive to monitor and make a record of these results. Even if this was done, there is no guarantee that a physician would have the time, or the ability, to correctly interpret the results due to the complexities mentioned above.

These arguments lead to the crux of the problem - cost. In order to make the extra readings truly beneficial to the patient, proper analysis of the results is crucial. This step is complex and time consuming. It is also, therefore, expensive. The manufacturers of glucose monitors are, of course, well aware of this and have developed data management software to assist with this process. However, patients are reluctant to leave treatment decisions in the hands of a computer programme. Furthermore, there are liability issues to consider as well.

\subsection{A Crowded Marketplace - Another Blockbuster}

There are, currently, over 40 blood glucose meters on the market. The major players are fighting to accomplish two objectives. Firstly, they need to at least maintain their current market share. Secondly, they need to expand the market itself, to include new users. The lion's share of the market is shared between Roche Diagnostics, Lifescan, Abbott and Bayer. These are very large companies, who have often resorted to a strategy of acquisition, rather than innovation. Consequently, existing technology has often been re-packaged and combined with an aggressive marketing campaign to achieve the above objectives. 
As Abbott has discovered, over the last few years, this strategy has a limited lifetime. At the end of 2003, Abbott's Medisense technology, which had been the most innovative and leading edge when it was introduced in 1987 (Turner \& Swain, 1988), was, arguably, the oldest and least novel of that offered by any of the major players. To make matters worse, they were losing market share to the "new kid on the block", Therasense. Abbott announced, in January 2004, an agreement to purchase the smaller, but dynamic Therasense business for $\$ 1.2$ billion in cash. The deal, at $\$ 27$ per share, would revive what many analysts and investors saw as a floundering division under the Abbott umbrella. Importantly, it provides Abbott with new, leading edge, and potentially lucrative, diabetes-testing technology.

Competition from reflectance devices continues to diminish, largely because of superior performance of the electrochemical biosensors, with their ability to give a rapid, accurate answer using a disposable strip, with no possibility of instrument contamination. The shift towards electrochemical biosensors has been most noticeable at Lifescan and Roche Diagnostics and explains the huge growth in biosensor sales by these companies over the past few years. It is also significant that the big players are starting to offer glucose with other analytes to increase their market share.

The biosensor market growth has been accelerating over the last six years, or so. However, it should be remembered, before one is tempted to extrapolate this trend, that there is a finite limit to the number of blood glucose biosensors that can be sold. A large proportion of the increased sales has resulted from the shift from reflectance technology. On the other hand, very large markets are emerging in countries which have, until recently, not featured heavily in the biosensor sales figures. China, in particular, not only has a huge population (and a correspondingly large number of diabetics), but it has entered the market, initially through the Shanghai New Genius Biotech Co. Ltd. It is almost certain that others will follow in China and in many other countries. It should also be mentioned here that many of the original patents have either lapsed, or will do so shortly. This will, inevitably, lead to a spread of devices, particularly in developing countries.

\section{Glucose Biosensor Technology}

Before discussing glucose biosensors, it is important to mention that the first successful blood glucose meters were not biosensors and that, for many years, biosensors accounted for only a small proportion of commercial sales in this arena.

Initially, the dominant technology was based on a reflectometer invented by Anton $\mathrm{H}$. (Tom) Clemens, whose work led to the launch of the Ames Reflectance Meter (Figure 1). At the time, Ames was a division of Miles Laboratories in Elkhart, Indiana, USA and is now part of Bayer Corporation. Interestingly, work on the meter was started in 1966, four years after Clark's description of the glucose biosensor (Clark \& Lyons, 1962), but development of the reflectometer was much faster. Several prototypes were built in 1968 for field trials and a patent application was filed in April of that year. A US patent (no. 3,604,815) for the meter was granted on September 14, 1971, about two years after it went on the market. 


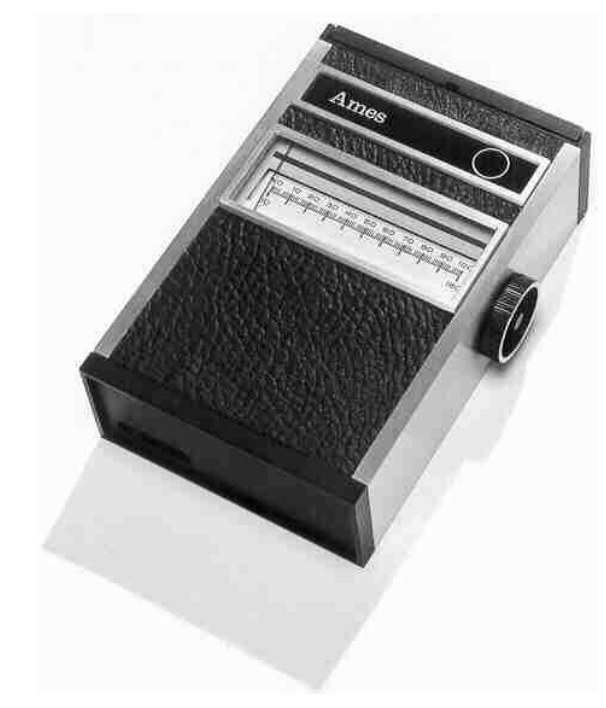

Figure 1: Ames Reflectance Meter

The original Ames Reflectance Meter was expensive and required a prescription. It was also rather large and heavy, weighing approximately $1 \mathrm{~kg}$. Despite this, the instrument was a success and eventually led to the Eyetone, the Ames Glucometer, and then to a great variety of other products.

In principle, many transducers could be used in a biosensor for the measurement of glucose, but in practice, electrochemistry has dominated. This is partially historical, but the primary reason for the success of devices of this type, is that they offer suitable sensitivity and reproducibility and, importantly, can be manufactured in great volume at low cost.

The most commonly used enzymes in the design of glucose biosensors contain redox groups that change redox state during the biochemical reaction. Enzymes of this type are glucose oxidase (GOx) and glucose dehydrogenase (GDH). In nature, oxidase enzymes such as GOx act by oxidising their substrates, accepting electrons in the process and thereby changing to an inactivated reduced state. These enzymes are normally returned to their active oxidised state by transferring these electrons to molecular oxygen, resulting in the production of hydrogen peroxide $\left(\mathrm{H}_{2} \mathrm{O}_{2}\right)$ :

$$
\text { Glucose }+\mathrm{O}_{2} \rightarrow \text { Gluconolactone }+\mathrm{H}_{2} \mathrm{O}_{2}
$$

Glucose may also be oxidised by GDH. One mechanism relies on $\mathrm{NAD}^{+}$acting as a cofactor, rather than oxygen as a cosubstrate. In this case NADH is produced:

$$
\text { Glucose }+\mathrm{NAD}^{+} \rightarrow \text { Gluconolactone }+\mathrm{NADH}
$$

A third mechanism involves the use of quinoprotein glucose dehydrogenase, which requires neither oxygen nor $\mathrm{NAD}^{+}$. Quinoproteins form a class of enzymes, which require ortho-quinone cofactors to oxidise a wide variety of alcohols and amines to their corresponding aldehydes and ketones. The soluble quinoprotein GDH uses pyrroloquinoline quinone (PQQ) as a cofactor.

$$
\text { Glucose }+ \text { PQQ(ox) } \rightarrow \text { Gluconolactone }+ \text { PQQ(red) }
$$


Each of the above enzyme mechanisms can be utilised in glucose biosensors but feature different advantages and drawbacks:

- The oxidase enzyme is inexpensive but requires oxygen as a cosubstrate. Consequently, as oxygen is depleted in the sample, performance decreases, whether one is monitoring oxygen depletion, or hydrogen peroxide production.

- $\mathrm{NAD}^{+}$dependent $\mathrm{GDH}$, on the other hand, is oxygen independent, and has the added attraction of being a well-established probe for monitoring biochemical reactions. The drawback is that the cofactors are relatively expensive and unstable.

- PQQ-GDH is a particularly efficient enzyme system, with a rapid electron transfer rate, but it is comparatively costly.

Combining these enzyme-based reactions with a suitable transducer enables selective sensor devices to be fabricated. The earliest approaches to the construction of amperometric glucose biosensors have been alluded to in the preceding sections. GOx can be immobilised close to an electrode and the depletion of oxygen can be monitored, using a Clark oxygen electrode as depicted in the schematic depicted in Figure 2.

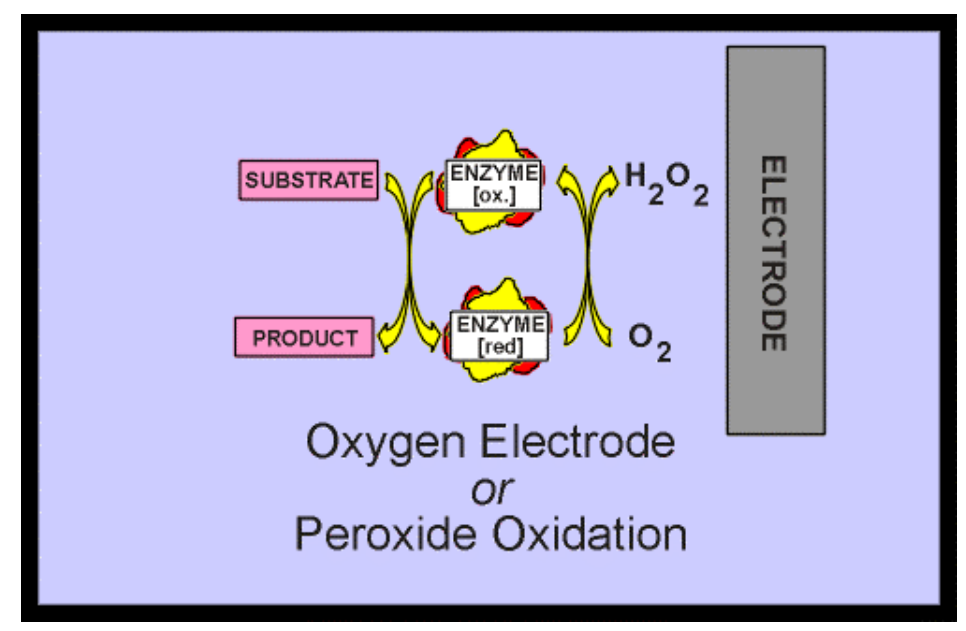

Figure 2: First Generation Glucose Biosensor Schematic

From this reaction scheme, it is apparent that it is also possible to measure glucose via the oxidation of the hydrogen peroxide produced by the enzymatic reaction, since this is directly proportional to the concentration of glucose. This can also be measured amperometrically at a potential of approximately $+0.7 \mathrm{~V}$ vs. $\mathrm{Ag} / \mathrm{AgCl}$, when a platinum working electrode is used.

Despite the cumbersome construction of biosensors based on this approach, Clark's ideas became commercial reality in 1975 with the successful re-launch (first launch 1973) of the Yellow Springs Instrument Company (Ohio, USA) glucose analyser based on the amperometric detection of hydrogen peroxide. These instruments have remained in the marketplace ever since. An early version, the model $23 \mathrm{~A}$ instrument 
is shown in Figure 3. Since then, this model and its successors have become a standard for clinical diagnostic work at many sites in the hospital and in chemistry laboratories worldwide.

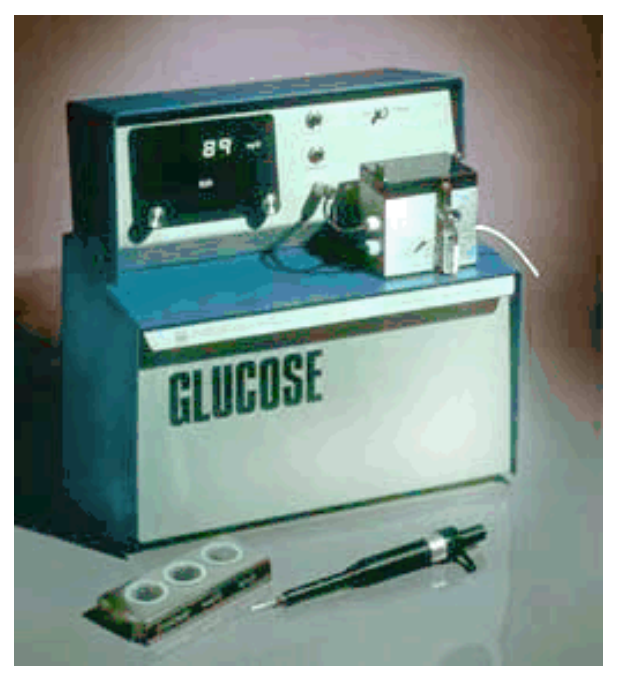

Figure 3: YSI 23A Glucose Biosensor

The original model 23A analyser has been superseded by more advanced machines, but the basic construction of the biosensor has changed little over the years. For glucose analysis, Glucose oxidase is immobilised between two membrane layers. The outer polycarbonate membrane retains the enzyme, allows glucose to pass, but prevents many larger molecules from entering, thus reducing interference. The glucose enters the enzyme layer, where it is oxidised, producing hydrogen peroxide. This passes through the cellulose acetate membrane to a platinum electrode where it is measured amperometrically. The second membrane acts as a further size exclusion barrier preventing many other potentially interfering (electroactive) compounds from reaching the electrode surface.

The construction of the YSI devices is relatively expensive, since it uses platinum electrodes. It is robust, but it is not straightforward to miniaturise and simplify its method of production. In addition, the rather high detection voltage required makes the system prone to interference in the absence of the membrane structures utilised.

Although very specific with regards to the reducing substrate, enzymes such as glucose oxidase show a high degree of flexibility with regard to the second substrate, i.e. the electron acceptor. Thus, many inorganic redox couples and organic dyes have been successfully utilsed as electron sinks for the glucose oxidase catalysed oxidation of glucose. In the early 1980s, it was realised that this method of operation facilitated a transfer of electrons in enzyme electrodes which was largely independent of the local oxygen concentration and allowed operation at much lower potentials, eliminating many of the problems associated with interference noted with the previously discussed devices. Working in collaboration with Oxford University, our team at Cranfield realised that the electron transfer compounds, which we were using to increase the efficiency of biofuel cells, held a great deal of promise in biosensor applications (Cass et al, 1984). These redox couples, or mediators, are able to shuttle electrons between the redox centre of the enzyme and the electrode. Depending on the compound used, they can also be regenerated at potentials where interference from 
species such as ascorbate, urate and paracetamol is minimal. The principle of operation is shown in Figure 4.

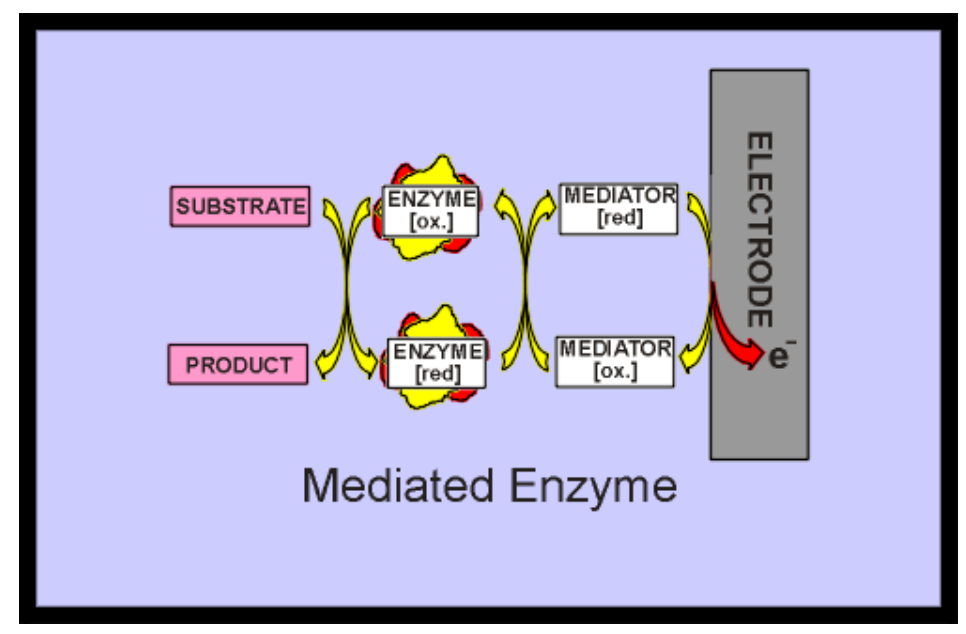

Figure 4: Mediated Biosensor Schematic

Arguably the most important examples of this class are mediators based on ferrocene and its derivatives. This can be attributed to three main factors: they have a wide range of redox potentials; the redox potentials are independent of $\mathrm{pH}$; and the synthetic schemes involved in making derivatives are usually straightforward. In order to ensure the electron transfer, the mediator must be present in both its oxidised and reduced forms, which must remain in the vicinity of the electrode. In some formats, this means that the mediator must be insoluble, but in certain designs, it is possible to use one that is soluble, as we shall see later, when some commercially-successful designs are discussed. The mediator should also have a rate constant for the reaction with glucose oxidase that is sufficiently competitive with the natural mediator, oxygen.

An advantage of blood glucose measurement is that it is acceptable to use a biosensor design that is suitable only for a single measurement. Indeed, when handling blood, it is seen as an advantage to have a disposable device. This is convenient from the point of view of using a mediated biosensor format, since one of the major drawbacks of most mediators is that they are relatively soluble, leading to short operational lifetimes and irreproducible results. This is even true of one of the most popular mediators, ferrocene, which, despite being relatively insoluble in its oxidised form, becomes quite soluble when reduced to the ferrocinium ion.

Mediators were the first of two key breakthroughs, which took glucose biosensors forward and allowed them to compete and eventually supercede reflectance devices for home testing of blood glucose. In order to do this, the biosensors needed to be inexpensive and small, which ruled out devices of the YSI type. An inexpensive and reproducible means of mass manufacture was required. Fortunately, the answer to this problem lay in a technique widely used in the electronics industry: screen-printing.

Screen-printing is a thick-film process, which has been used for many years in artistic applications and, more recently, for the production of miniature, robust and cheap 
electronic circuits. During the early 1980s, the process was adapted for the production of amperometric biosensors and this has had a huge impact on their commercialisation (Zhang, 2004). The majority of the most successful electrochemically-based devices to date have used this technique.

Screen-printing involves squeezing a suspension (usually referred to as an ink, due to the origins of the technique) through a patterned screen onto a solid support (substrate) held on the reverse of the screen. Hence, the process is very simple and rapid. Multiple repeat patterns are usually designed onto a single screen, further enhancing production speed. A small pilot-scale machine, such as that shown in Figure 5, is able to produce many thousands of sensors per day. Larger machines are available, and can greatly exceed this production figure.

The process has been one of the major reasons for the commercial success of many biosensors and is the process by which MediSense produced the original ExacTech electrodes and now, as part of Abbott Laboratories, produce well over 1 billion biosensor strips annually.

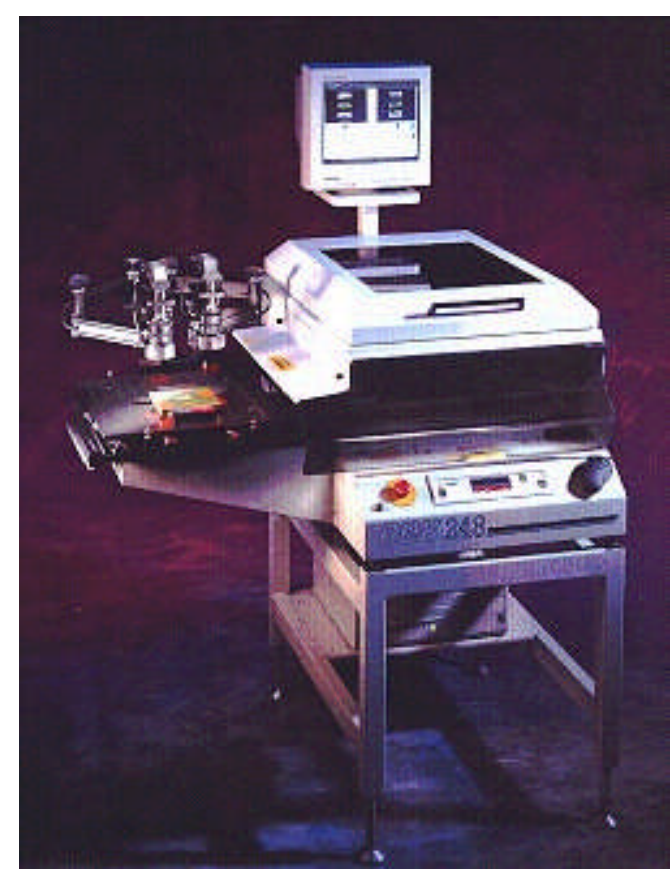

Figure 5: Laboratory-Scale Screen-Printer

The full commercial impact of the technology was initially limited by the range of inks available for the construction of inexpensive devices. Ceramic substrates were often used, mainly for their temperature resistance and rigidity and inks were developed with properties, which were good for microelectronics uses, but poor from a biosensor standpoint.

Today, inks based on carbon and many metals are widely available for low temperature applications (Newman et. al. 1995). However, there are a number of metals which cannot be printed using low temperature curing. Temperatures of up to $850^{\circ} \mathrm{C}$ are often required to cure inks employing gold and many other useful electrode materials and, hence, costly ceramic substrates are still often required. It is not 
impossible to produce relatively inexpensive devices using ceramic bases, but polymeric materials are cheaper and easier to process.

There is now a wide array of inks suitable for producing biosensors. Most of the applications to date have involved electrochemical devices, but the technique is applicable to the production of any planar device. Some defining moments in the evolution of commercial glucose biosensors are listed in Table 1.

\section{Table 1: Some Defining Events in the History of Commercial Biosensor Development}

\begin{tabular}{l|l} 
DATE & EVENT \\
\hline $\mathbf{1 9 1 6}$ & $\begin{array}{l}\text { First report on the immobilisation of proteins: adsorption of } \\
\text { invertase on activated charcoal }\end{array}$ \\
$\mathbf{1 9 2 2}$ & $\begin{array}{l}\text { First glass pH electrode } \\
\text { Invention of the oxygen electrode (Clark) }\end{array}$ \\
$\mathbf{1 9 5 6}$ & $\begin{array}{l}\text { First description of a biosensor: an amperometric enzyme electrode } \\
\text { for glucose (Clark \& Lyons) }\end{array}$ \\
$\mathbf{1 9 7 3 - 7 5}$ & $\begin{array}{l}\text { First commercial biosensor: Yellow Springs Instruments glucose } \\
\text { biosensor }\end{array}$ \\
$\mathbf{1 9 7 6}$ & $\begin{array}{l}\text { Miles Biostator: first bedside artificial pancreas } \\
\text { First fibre optic-based biosensor for glucose (Schultz) }\end{array}$ \\
$\mathbf{1 9 8 4}$ & $\begin{array}{l}\text { First mediated amperometric glucose biosensor: ferrocene used } \\
\text { with glucose oxidase for the detection of glucose (Cass } \text { et. al. })\end{array}$ \\
$\mathbf{1 9 8 7}$ & $\begin{array}{l}\text { Launch of the MediSense ExacTech blood glucose biosensor } \\
\text { i-STAT launches hand-held blood analyser }\end{array}$ \\
$\mathbf{1 9 9 2}$ & $\begin{array}{l}\text { Glucocard launched } \\
\mathbf{1 9 9 6}\end{array}$ \\
$\mathbf{1 9 9 6}$ & $\begin{array}{l}\text { Abbott acquires MediSense for } \$ 867 \text { million } \\
\mathbf{1 9 9 8}\end{array}$ \\
$\mathbf{1 9 9 8}$ & $\begin{array}{l}\text { Merger of Roche and Boehringer Mannheim to form Roche } \\
\text { Diagnostics }\end{array}$ \\
$\mathbf{2 0 0 1}$ & $\begin{array}{l}\text { LifeScan purchases Inverness Medical's glucose testing business } \\
\text { for } \$ 1.3 \text { billion } \\
\text { i-STAT acquired by Abbott for } \$ 392 \text { million } \\
\text { Abbott acquires TheraSense for } \$ 1.2 \text { billion }\end{array}$ \\
$\mathbf{2 0 0 3}$ & \\
$\mathbf{2 0 0 4}$ &
\end{tabular}

\subsection{Evolution of the Species}

Most glucose monitors operate by measuring glucose in blood samples obtained from the finger, using a small lancet. This has several implications, which have influenced the design of monitors and the development work being undertaken by the companies involved in their sale:

- Since blood is being handled, a disposable sensor design is preferred

- Minimising the required sample size is a priority

- Finger-pricking is uncomfortable, so other sampling sites have been investigated

- Instrument design has become more automated

The first really successful blood glucose biosensor for home-use was a mediated device based around a disposable, screen-printed sensor design. It was developed by a 
company, which was originally called Genetics International, in conjunction with the Universities of Cranfield and Oxford. The company was renamed MediSense and the product that was launched was the ExacTech device (Figure 6).

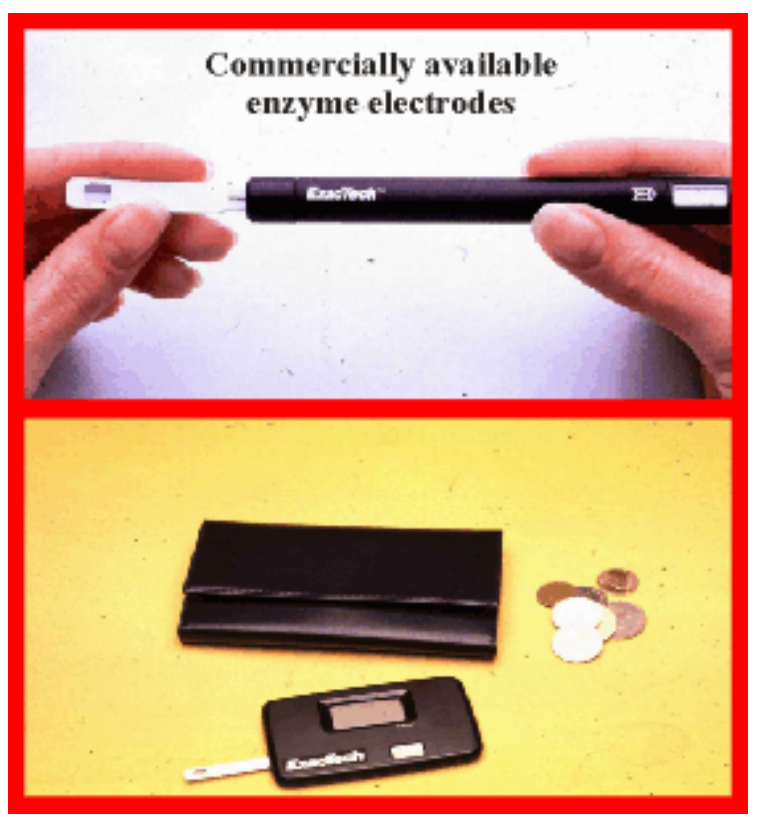

Figure 6: Original MediSense Products

Until very recently, all subsequent MediSense (now owned by Abbott) products have utilised similar technology. The basic concept involves an amperometric biosensor, employing glucose oxidase and electrochemical mediators on a disposable strip format. Various improvements have been incorporated since the launch of the original devices, in 1987, but the concept has remained largely unaffected. The instrument itself has also evolved from the original pen-shaped device, through a credit card format and on to an ergonomic design resembling a computer mouse.

\subsection{Current Generation of Home Blood Glucose Monitors}

The biosensor market is dominated by a small number of large diagnostic companies. These have achieved this position of strength through a variety of means, but acquisition comes high on that list. Abbott is the king of the acquisition game. In 1996, it purchased MediSense for $\$ 867$ million, immediately catapaulting them to the forefront of the biosensor business world. Roche merged with Boehringer Mannheim thus acquiring Boehringer's strong biosensor portfolio, to form Roche Diagnostics in 1998, a move which was to provide a boost to both businesses. The combined might of Roche and Boehringer, in terms of marketing and product strength, meant that the joint business outperformed the sum of the two parts. Lifescan, the then market leader in glucose monitoring, responded to this move by acquiring the glucose testing business from Inverness Medical in 2001. Abbott, once more, was under threat and responded with the purchase of Therasense, for $\$ 1.2$ billion, in 2004. 


\subsubsection{Abbott Laboratories}

The Exactech (shown in Figure 6) was the original Medisense biosensor concept. It is a whole-blood calibrated meter, with no data port. Improvements in ergonomics have led to an easier to read display and a simpler to use instrument. Closely related to this product is the ExacTech RSG ${ }^{\mathrm{TM}}$, which also lacks a data port. Both instruments require a $10-50 \mu 1$ drop of blood and 30 seconds to test.

A variant of the ExacTech ${ }^{T M}$ is also made by MediSense ${ }^{T M}$ : the WalMart ReliOn ${ }^{T M}$ brand of blood glucose meter (Figure 7) is, currently, the lowest cost meter and test strip supply on the market and is available solely through WalMart pharmacies.

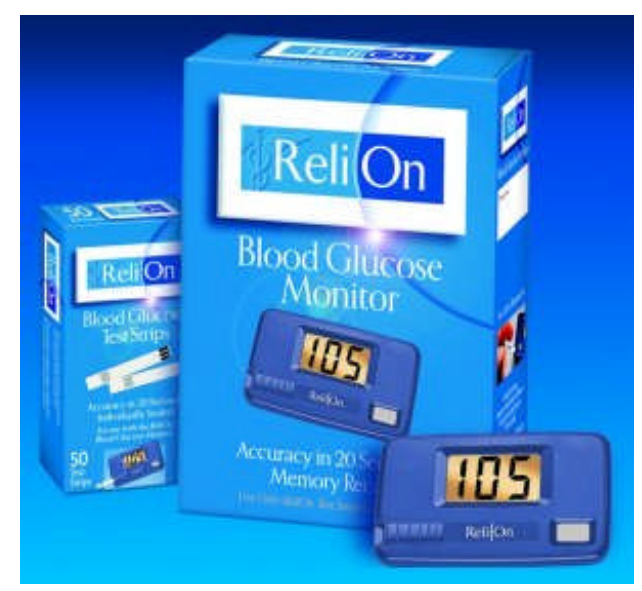

Figure 7: Walmart ReliOn Blood Glucose Monitor

Other variants followed, each of which was based on similar principles, but offered different features and improvements. The Precision QID ${ }^{T M}$ meter contains strips which are plasma-blood calibrated. It tests in 20 seconds and requires $3.5 \mu 1$ of blood. If the sample is too small, more can be added within 30 seconds. It has memory recall of the last 10 results. In addition, a data port allows up to 125 test results to be downloaded to an office or home computer with the optional Precision Link® software program for further analysis. Results are analysed in various ways for more effective decisions and designed to support patient log book involvement.

The PCx instrument also requires $3.5 \mu \mathrm{l}$ of whole blood to provide accurate results within 20 seconds and an audible signal that tells the operator that an adequate sample has been provided. Automatic initiation of the test procedure occurs once a sample has been detected; and laser barcode scanning for all data entry eliminates manual entry errors. Results for up to 4000 tests can be stored in the monitor itself, and can be easily retrieved for review. Precision $\mathrm{PCx}^{\mathrm{TM}}$ test strips provide glucose results from 20 to $600 \mathrm{mg} / \mathrm{dl}$ across a 20 to 70 percent haematocrit range.

The MediSense Sof-Tact ${ }^{\mathrm{TM}}$ is the first glucose monitor to offer lancing, blood collection, and glucose testing with a single press of a button. In addition to the convenience of automated testing, the system offers users an easy and virtually painless method of obtaining blood samples, because the device allows blood to be drawn from less sensitive areas of the body such as the forearm or upper arm using 
suction (Figure 8). The meter also employs new strip technology, which requires only $2-3 \mu 1$ of blood. Results are produced in 20 seconds. The meter has a 450 test result memory, records time and date and shows 7,14 , and 28 day averages. A data port allows it to work with diabetes management software. This device is also plasmablood calibrated. Limitations of this device include a poorer than predicted up take of alternate site testing, the considerable size of the instrument and the restriction to a single measurement (compared with offerings from Pelikan, Bayer and Roche).

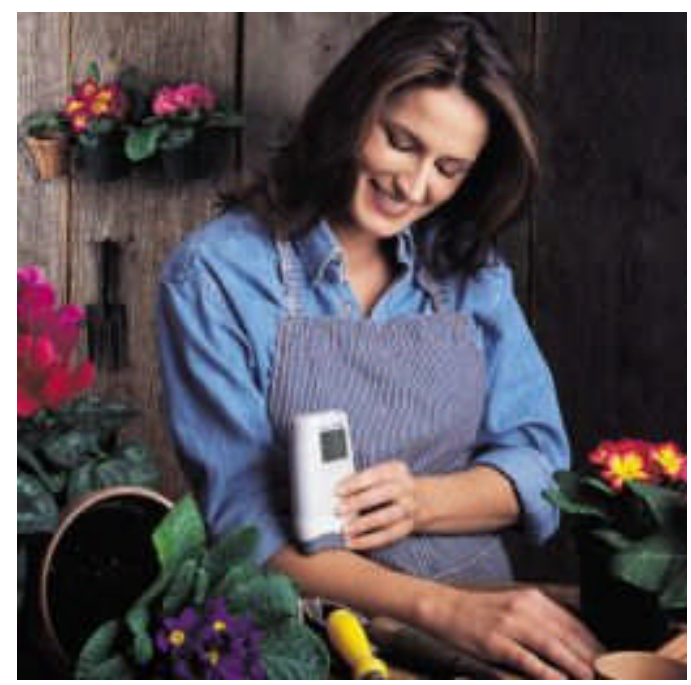

Figure 8: Sof-Tact Monitor

The latest product is the Precision Xtra ${ }^{\mathrm{TM}}$ (Figure 9), the first personal blood glucose meter that also allows people with diabetes to test their blood for ketones. This is an important addition to the range, since over one million diabetics, in the US alone, are at risk of developing diabetic ketoacidosis (DKA), a life-threatening condition that can result in coma or death.

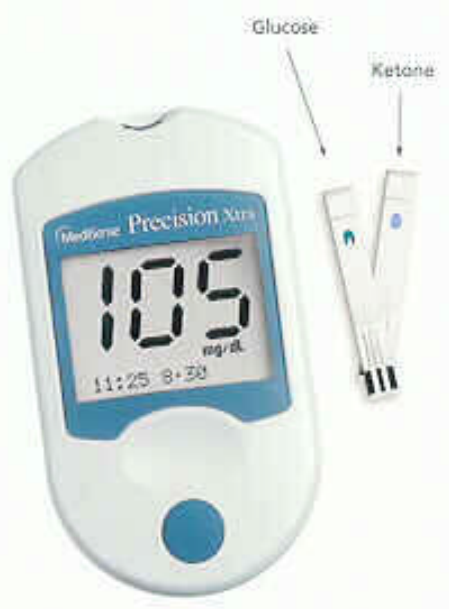

Figure 9: Precision Xtra ${ }^{\mathrm{TM}}$ Glucose / Ketone Monitor 
Precision Xtra ${ }^{\mathrm{TM}}$ tests ketone levels in blood, in real time, which was not possible with existing devices, since they measure ketones in urine. It measures B-hydroxybutyric acid, the predominant ketone in the body. In a co-branding agreement with PolyMedica Corporation (Woburn, MA, USA), its Liberty subsidiary sells the Precision Xtra as the Optium blood glucose meter. This product has taken on particular significance since Abbott acquired Therasense since they are now rationalising their portfolio by promoting the superior Therasense glucose sensor range while pushing the Pecision Xtra from the MediSense range.

In June 2001 a new blood glucose product received FDA marketing clearance. The test strip utilises MediSense's newly developed TrueMeasure ${ }^{\mathrm{TM}}$ technology. The new strips, which represent fifth-generation test strip technology, incorporate several advanced features and benefits designed to enhance the accuracy of test results for people with diabetes. The product incorporates a three-electrode design into the strip, which is specifically designed to act as a trigger, starting the glucose test only after a sufficient blood sample is applied.

It also utilises a proprietary new test chemistry that minimises false low and high readings caused by interfering substances. The new chemistry is more specific for identifying glucose and, during testing, displayed no interference from more than 60 common medications and over-the-counter products including vitamin $\mathrm{C}$ and paracetamol (acetaminophen). In addition to the three-electrode design and new test chemistry, the test strip can be used as either an end-fill or top-fill strip, a feature that makes applying the blood sample simpler and more convenient. People using these test strips have the option of applying blood samples to both the end and top of the test strips, whichever is more comfortable for them. The strips incorporate a semiopaque cover for visual confirmation that a blood sample has filled the test chamber. The cover allows testers to quickly see if a second drop of blood needs to be added to conduct the test. Additional blood can be added within 30 seconds if necessary, thereby reducing strip waste. The new strip is compatible with existing Precision $\mathrm{Xtra}^{\mathrm{TM}}$ and Optium ${ }^{\mathrm{TM}}$ meters and will be used by future meters introduced by the company.

Therasense, which was acquired by Abbott in 2004, has developed a coulometric glucose analyser, which utilises pyrroloquinoline quinone (PQQ) glucose dehydrogenase in a $50 \mu \mathrm{m}$ gap thin layer cell. The company's first product is the FreeStyle $^{\mathrm{TM}}$ Blood Glucose Monitoring System, which was launched in June 2000. This device allows patients to measure glucose in just $0.3 \mu \mathrm{l}$ of blood, which is the smallest volume required for any related commercial device currently on the market. As a result, the pain associated with testing is greatly reduced, which should encourage more frequent testing and hence better control of the disease. The system allows samples to be taken from multiple sites including the fingertips, forearm (Figure 10), upper arm, thigh, calf and fleshy part of the hand. 

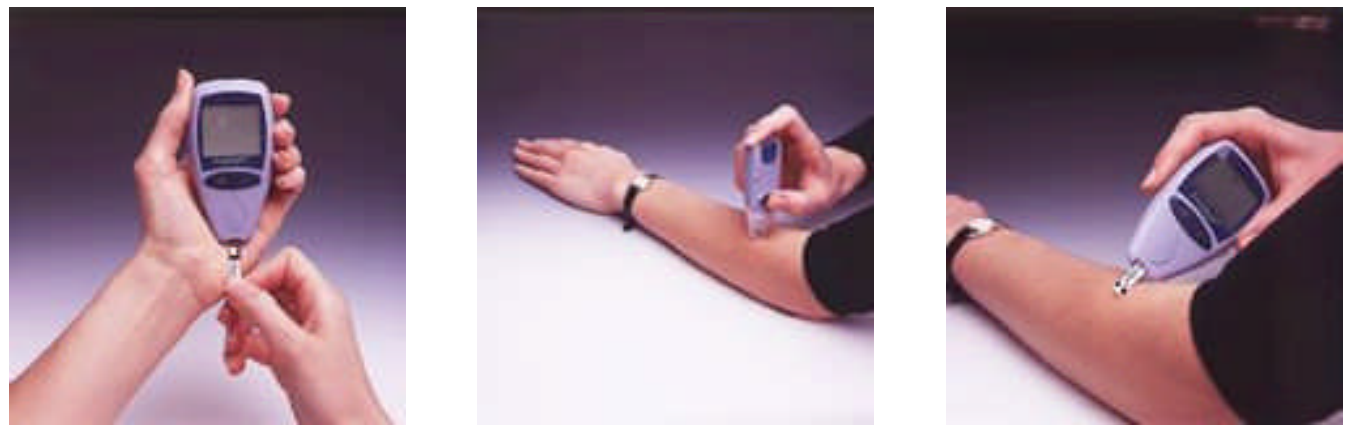

Figure 10: Monitoring Blood from the Forearm Using FreeStyle Meter

Workers at TheraSense ${ }^{T M}$ have investigated multiple site sampling intensively. It was found that changes in glucose levels are detected more rapidly in the finger tip than in the arm, but that this effect can be significantly reduced, by rubbing the arm prior to sampling. As shown in Figure 10, the meter is operated on the forearm using the normal three steps: Insert, Lance, Touch.

Insertion of the test strip automatically turns the meter on. A small sample is drawn into the test strip. An audible beep signals when the strip is full. Following this, a response time of approximately 15 seconds is common. The unit automatically shuts off 2 minutes after last user action. The FreeStyle Connect ${ }^{\mathrm{TM}}$ Data Management System allows the user to download meter data into a PC. It can then be quickly reviewed, analysed and printed in any of several report formats. A custom data cable to connect the FreeStyle ${ }^{T M}$ meter to the user's PC is required for patient safety and this is supplied as standard. For households with more than one person testing their blood glucose, the software allows multiple users to download data. Meter data is tracked and reported by meter serial number.

\subsubsection{Bayer Diagnostics}

Bayer Diagnostics' primary biosensor products are for rapid blood glucose monitoring, an area it first became involved in when it introduced Dextrostix ${ }^{\mathrm{TM}}$, the first dry reagent colorimetric blood sugar test, in 1964. The company markets a range of instruments and accessories for both home and hospital use (see also KDK Corporation and Menarini entries). Bayer has, recently, renamed its range of blood glucose devices. The Ascensia ${ }^{\circledR}$ family of self-testing products includes sensors for use at home, or when out and offer alternate site testing. In addition to blood glucose testing systems, the Ascensia portfolio of products offers an array of tools including data download and analysis software, an award-winning finger-lancing device, an alternate-site lancing device and support for people with diabetes. 

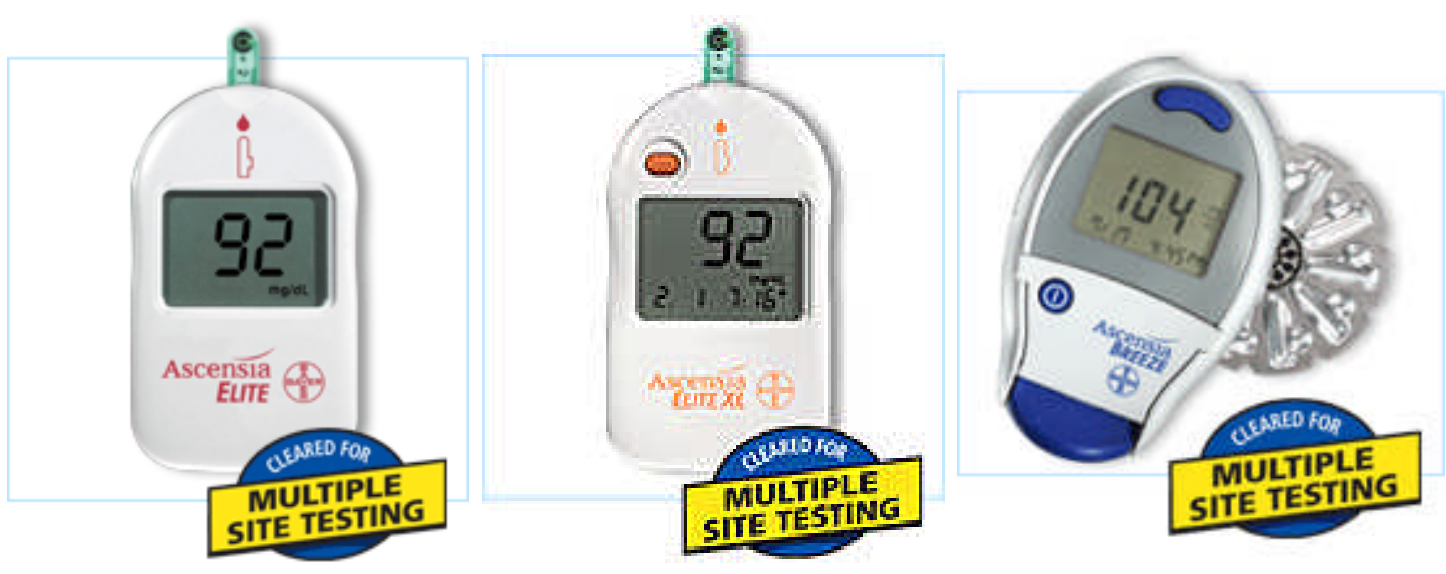

Figure 11: Ascensia Elite, Elite XL and Breeze Biosensors

Ascensia Elite (Figure 11) is the basic system, which features button-free operation and, like all Ascensia instruments, alternate site sampling capability. It operates via capillary-fill and provides an answer within 30 seconds. A 20 test memory is built in. The Elite $\mathrm{XL}^{\mathrm{TM}}$ product is similar, but has improved data handling, including a 120 test memory and computer connectivity. This device has neonatal and arterial capabilities, so is suitable for the hospital environment as well. The Breeze instrument follows Bayer's original innovation of multiple test discs using a 10 test disc for added convenience. Following Bayer's lead, multiple test discs or drums are rapidly becoming a standard offering with similar products on sale from Roche and announced by Pelikan.

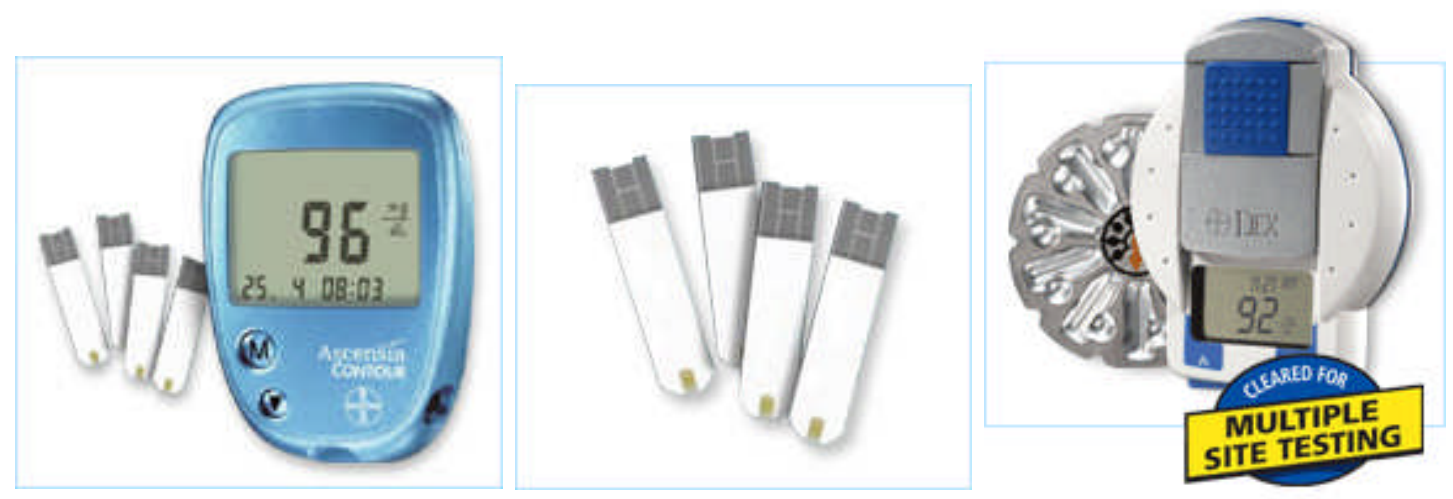

Figure 12: Ascensia Contour, Microfill Sensors and Dex 2

The latest instrument is the Contour ${ }^{\mathrm{TM}}$ (shown in Figure 12), which uses Bayer's Contour micofill sensors, and requires $0.6 \mu \mathrm{l}$ of blood. No coding is required and there is an underfill warning. Testing time is 15 seconds and up to 240 results can be stored. The lack of coding is a popular feature basically achieved by tighter quality control resulting in the penalty of a higher rejection rate and consequent lower margin on this specific product. Data management can be carried out on a PC using GLUCOFACTS ${ }^{\mathrm{TM}}$ diabetes software. Finally, the DEX $2^{\mathrm{TM}}$ system uses the Autotest ${ }^{\mathrm{TM}}$, 10 sensor cartridge.

Bayer also has a substantial urinalysis business, based at present on fairly standard test strip technology, using approaches such as lateral flow assays. At the moment 
these can feature numerous tests on a single strip, which can be read using a reflectance approach. New immunocasettes are available for a number of urine proteins. The company is, however, developing more advanced systems based on microfluidics. In collaboration with Steag Microparts, Bayer is developing Chem Chips and Immuno Chips for a number of analytes, including glucose and uric acid.

\subsubsection{LifeScan}

LifeScan markets a range of blood glucose monitoring products under the One Touch $^{\mathrm{TM}}$ product umbrella. The company's position in the market was strengthened in 2001 by the acquisition of the diabetes care business of Inverness Medical. Lifescan has several devices on the market.

The One Touch FastTake ${ }^{\mathrm{TM}}$ test strips feature the FastDraw ${ }^{\mathrm{TM}}$ design, which automatically pulls blood into the test strip, so it is no longer necessary to target blood onto the top of the strip. This is aimed at making testing more comfortable, with a reduced blood sample, enabling finer tip lancet to be used, which means less pain. The meter also allows testing via the arm or fingertips. Results are displayed after 15 seconds. The instrument is now available only through mail order, although the test strips are still on general release.

One Touch Profile ${ }^{\mathrm{TM}}$ contains a data port, which allows it to work with diabetes management software. This is a whole blood-calibrated meter. It has now been withdrawn from sale, although Lifescan intends to continue to provide full support for users and, for the time being, they still produce the strips.

The One Touch Ultra ${ }^{\mathrm{TM}}$ Blood Glucose Monitoring System (Figure 13), features a five second test time and advanced electrochemical biosensor test strips that require just $1 \mu 1$ of blood. There is an option of finger or arm testing. It has a data port and uses the LifeScan In Touch ${ }^{\mathrm{TM}}$ software. This meter is plasma-blood calibrated.

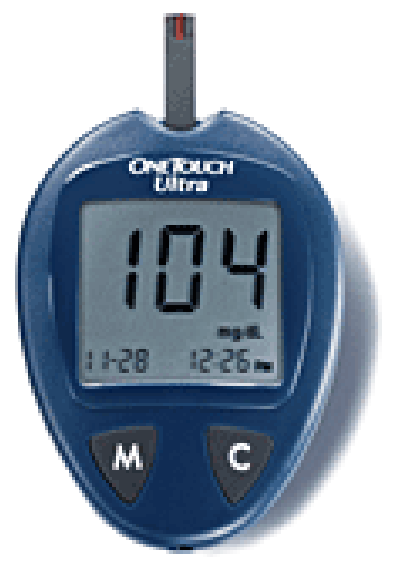

\section{Figure 13: OneTouch Ultra Blood Glucose Biosensor}

The UltraSmart ${ }^{\mathrm{TM}}$ system (Figure 14) incorporates an electronic logbook, which allows the user to track the things that affect their diabetes as well as measuring their 
blood glucose. Food intake, exercise and medication taken are all entered and all of the information can be displayed in such a way as is readily understandable.
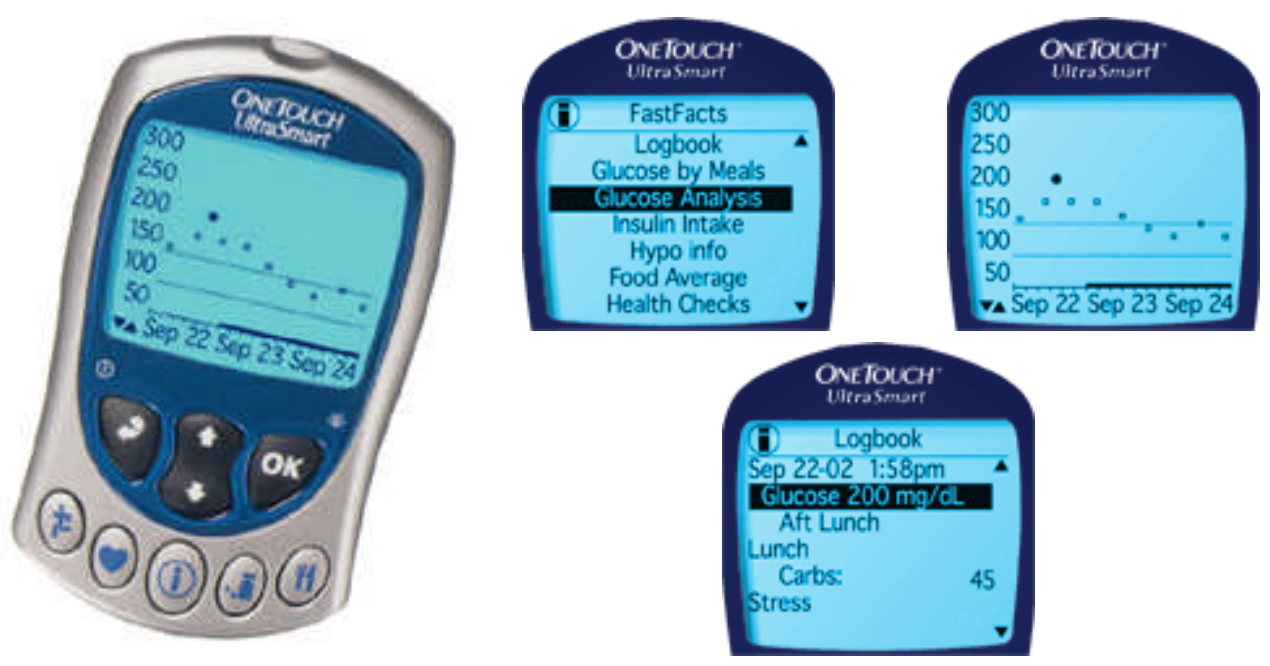

Figure 14: LifeScan UltraSmart System

LifeScan's InDuo ${ }^{\mathrm{TM}}$ system (Figure 15), is another variant of the Ultra meter and uses the same strips. In this case, it incorporates an insulin dosing system, which remembers the time and amount of your last dose. Developed and produced through a collaboration with Novo Nordisk (Bagsværd, Denmark), InDuo ${ }^{\mathrm{TM}}$ combines the latest technology pioneered by these two companies in one device. Insulin is delivered in Penfill ${ }^{\circledR} 3 \mathrm{ml}$ insulin cartridges including NovoRapid® (NovoLog® in the US) a rapid-acting insulin analogue. The combination of these functions in one device is aimed at helping people using insulin to better manage their diabetes, by establishing the important connection between blood glucose testing and injecting insulin. It is also more convenient, as it is one less item to carry around.

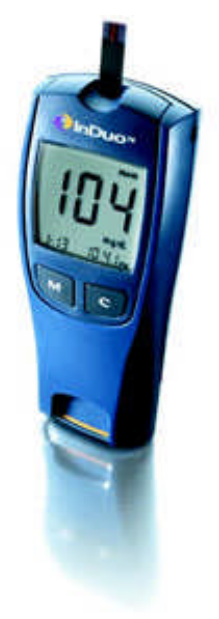

Figure 15: InDuo Combined Meter and Insulin Dosing System 


\subsubsection{Roche Diagnostics}

The main biosensors products sold by Roche are the Accu-Chek ${ }^{\mathrm{TM}}$ blood glucose monitoring systems. Accu-Chek Active ${ }^{\mathrm{TM}}$ (Figure 16) is one of the fastest meters in the market, requiring just 5 seconds to obtain a reading. It features an automatic on/off function, a $1 \mu \mathrm{l}$ blood sample requirement, 200 value memory storage (with times and dates, 7 and 14 day averaging and an underdosing monitor that detects when insufficient blood has been applied.

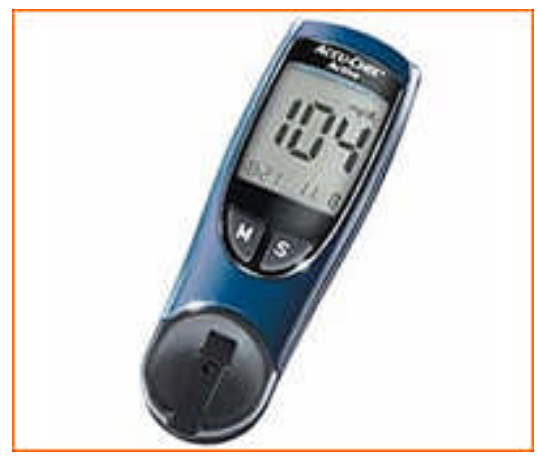

Figure 16: Accu-Chek Active Meter

The Accu-Chek Advantage ${ }^{\mathrm{TM}}$ (Figure 17) is Roche's top-selling meter (known in some countries Accu-Chek Sensor). The system requires just two simple steps and uses a snap-in code key, which makes calibration extremely simple. A 100-value memory automatically stores results along with times and dates. The system uses Accu-Chek Comfort Curve ${ }^{T M}$ test strips, which are shaped to assist blood application and reduce the sample size required. The side-fill capillary action requires that drop of blood is drawn into the strip, with minimal difficulty. The Accu-Chek Advantage can be used with the Accu-Chek Voicemate ${ }^{T M}$, a system which provides voice prompts to help those who have reduced vision. The system can even help identify the type of insulin in a vial.

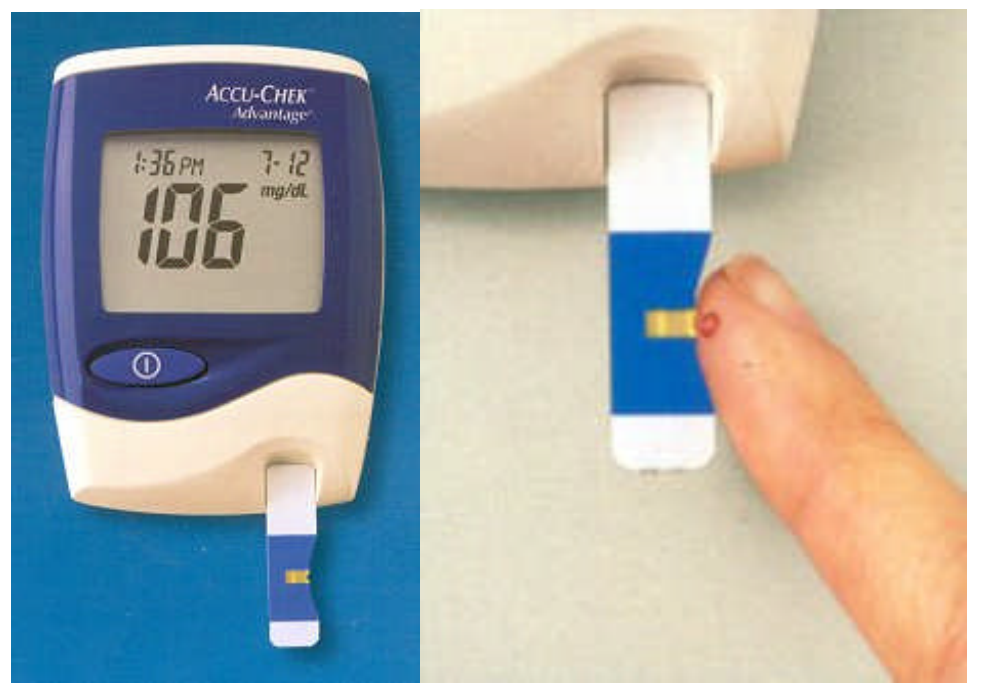

Figure 17: Accu-Chek Advantage Glucose Monitor Featuring Comfort Curve Test Strip 
Accu-Chek Compact (Figure 18) is a blood glucose self-monitoring system with integrated test strip drum. It features 17 test strips in a single drum that is fully integrated into the meter, which avoids the need for handling of individual strips. At the touch of a button, the monitor reads the barcode on the drum, codes the meter and moves the test strip to the correct right measurement position. It provides a result in 13-15 seconds and requires a 3-3.5 $\mu 1$ blood sample. After use, the strip is ejected automatically at another touch of the button. As with the Advantage system, up to 100 values can be saved, with dates, times and seven-day averaging.

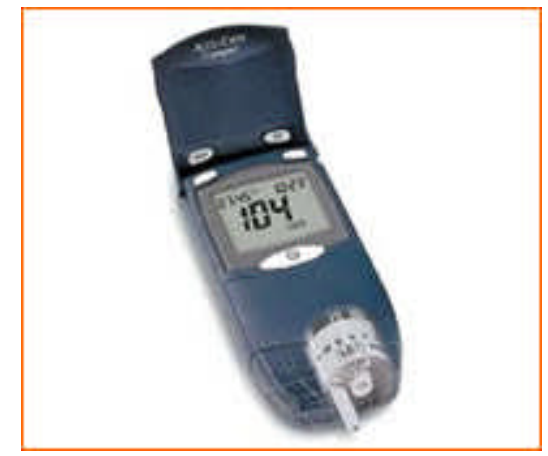

Figure 18: Accu-Chek Compact ${ }^{\mathrm{TM}}$ Instrument

Accutrend® GC, GCT and lactate allow measurement of: glucose and cholesterol (GC); glucose, cholesterol and triglycerides (GCT); and lactate. These systems use capillary blood and are suitable for home use of patients under medical supervision. At present, they all utilise reflectance technology but are mentioned because they demonstrate Roche's strategy in expanding their home testing range, although there appears to be no evidence that a change to biosensor technology is imminent.

\subsection{Improved Systems and Future Developments}

An elegant solution to elimination of interference in biosensors is to seek connection of the redox centre of the enzyme to the electrode via a molecular wire. This can be achieved by modifying the enzyme, the transducer, or both.

For example, $\left\{\right.$ Poly [1-vinylimidazole osmium $\left.\left.\left.\left(4,4^{\prime} \text {-dimethyl bipyridine }\right)_{2} \mathrm{Cl}\right)\right]\right\}^{(+/ 2+)}$ (Vijayakumar et al., 1996) has been used to 'wire' the enzyme. An enzyme electrode was then constructed by mixing the wired glucose oxidase into carbon paste. The electrodes, which were uncoated, but cross-linked with poly(ethylene glycol) diglycidyl ether, responded linearly to glucose concentrations up to $60 \mathrm{mM}$. The device effectively rejected common interferences such as ascorbic acid and paracetamol when present at their physiological concentrations. These principles formed the basis for the notable commercial success of the Therasense range of sensors.

Alternatively, enzymes can be functionalised using artificial cofactor derivatives (Katz \& Willner, 2001). Glucose oxidase, for example, has been deposited on an electrode surface functionalised with a relay (PQQ)-FAD monolayer. The resulting sensor exhibited bioelectrocatalytic properties with unusually high current densities (300 $\mathrm{mA} \mathrm{cm}^{-2}$ at $80 \mathrm{mM}$ of glucose). Furthermore, the efficient wiring of the enzyme 
makes glucose sensing unaffected by oxygen fluctuations and minimises the effect of other interferents.

Another approach is effected via a single molecule with delocalised electrons. Heteroarene oligomers, consisting of two pyridinium groups, linked by thiophene units of variable length (thienoviologens) are promising candidates for such conducting molecular wires and may be used in conjunction with self-assembly techniques to produce an insulated electrode which transfers electrons specifically along predetermined molecular paths (Albers et al., 1997). This design should produce enzyme electrodes free from electrochemical interference.

\subsection{Implantable Glucose Sensors}

The "holy grail" in terms of diabetes treatment is seen by some to be the successful introduction of an artificial pancreas. In order to facilitate continuous subcutaneous insulin infusion, with a portable and stable delivery system, it is necessary to undertake frequent, or preferably continuous glucose measurements. An implantable glucose measurement system is seen as a key component of such a closed-loop glycaemic control system. Many of the approaches described in previous sections have been applied in the quest for reliable in vivo sensing devices. Such sensors can be broadly classified into intravenous and subcutaneous categories.

Unfortunately, the development of in vivo measurement systems is not straightforward. There are numerous problems, which have proven difficult to overcome. These include:

- Sensor stability, which is particularly problematic when a biosensor approach is employed.

- Calibration - it is not a trivial process to relate the sensor reading to blood glucose levels.

- Biocompatibility - rejection of the sensor by the body is difficult to suppress.

The biocompatibility issue is, arguably, the greatest hurdle to be overcome. There are numerous effects, but from a sensing point of view, the major problem is build-up of tissue around the sensor as a result of its implantation, which affects diffusion to and from the sensor and results in readings that do not accurately reflect current blood glucose levels.

A major historical advance in the in vivo application of glucose biosensors was reported by Shichiri et al (1982) who described the first needle-type enzyme electrode for subcutaneous implantation. In early 2000, after a long research programme, MiniMed (Sylmar, CA, USA) began human testing of an implantable subcuntaneous blood glucose sensor (Figure 19), which led to its successful launch in 2002. MiniMed has limited FDA clearance for its product, which currently restricts access of the information obtained, to the physician. No access by the patient is currently accepted. 


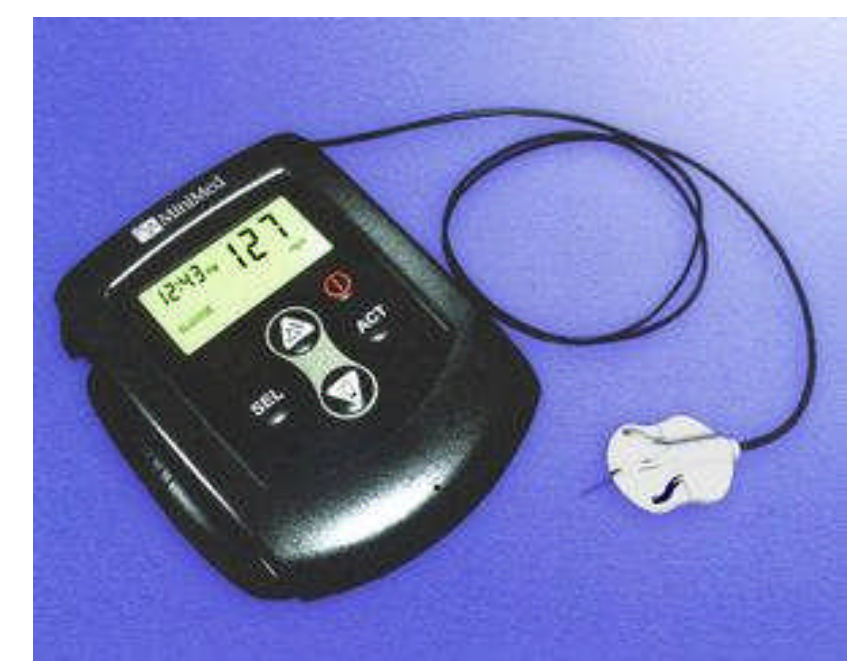

Figure 19: MiniMed ${ }^{\mathrm{TM}}$ Implantable Glucose Sensor

Therasense (Alameda CA, USA), has also developed a miniaturised subcutaneous sensor designed for insertion into the skin by the user to continuously monitor glucose levels and provide immediate results while also storing the results for future analysis. A major difference is that the Therasense needle is less than $10 \%$ of the length of Minimed's. Therasense designed their system to measure interstitial fluid, which requires a needle only long enough to cross the outer dermis and makes the needle essentially pain-free. It is a wireless system, intended for use with a "pager unit" that displays glucose levels. It can be conveniently carried or kept close to the bed at night. Several other implantable sensors, from other manufacturers are in development and are claimed to be close to market.

MiniMed (Sylmar CA, USA) has also been refining an artificial insulin pump, which is implanted under the skin of the abdomen through a minor surgical procedure. The pump is designed to be refilled in a physician's office every three months. For a patient, this can mean going from four injections per day to four injections per year. The implantable pump delivers basal rates of insulin and larger bolus doses, which are currently controlled by the patient through the use of a hand-held communicator that uses radio frequency telemetry. The MiniMed implantable pump has been in use since 1990, since when approximately 700 patients have received these through clinical trials. The company's current implantable pump, the Model 2007, received European approval in 2000 and has a projected 10-year battery life. In a further extension of this programme, MiniMed are working on a sensor located in a central vein leading to the heart through a minor surgical procedure. It records glucose levels once per minute and is designed to be replaced after one to two years. The sensor is designed to communicate directly with an implantable pump, with the eventual goal of "closedloop" control using continuous glucose information to automatically regulate insulin delivery.

A different approach is being adopted by Animas (Frazer, Pennsylvania, USA), with the aim of developing a long-term ( $>5$ years), implantable, sensor, which will provide continuous and accurate monitoring of blood glucose levels. This device will be equipped with alarms to give warnings of impending hypoglycaemia and hyperglycaemia. Ultimately the aim is to link the sensor to an insulin infusion pump 
to provide closed-loop control of blood glucose levels. The Animas sensor measures the near-infrared absorption of blood, and it will be implanted across a vein with readings transmitted via radio wave $(\mathrm{RF})$ telemetry to a small display unit worn on the wrist. Hence, there will be no percutaneous wires. The display unit will be about the size of a wrist-watch and the implanted sensor about the size of a pager.

Spectroscopic determination of glucose in blood has proved difficult because glucose is in relatively low concentration and its spectra overlaps that of other blood constituents, such as proteins, urea, uric acid, haemoglobin and even water. Many attempts to measure glucose through the skin or mucous membranes have failed, due to loss of light energy in the intervening tissues and the problem of extracting the blood spectra from that of intervening tissues. The Animas sensor sidetracks these limitations because the sensor is implanted and, therefore, has direct access to blood. A further advantage is that the system offers the potential to overcome many of the limitations of other chemical sensors and biosensors associated with biocompatibility and the encapsulation tissue which forms around implanted sensor devices. At the selected wavelengths used, this tissue is transparent. At present, the device has been demonstrated over a course of at least two weeks on an in vivo basis in dogs. The company is in the progress of designing a miniaturised sensor, which is currently undergoing preliminary human trials.

\subsection{Minimally-Invasive Systems}

In an attempt to minimise the discomfort caused by regular fingerpricking and to overcome the significant problems inherent in the introduction of in vivo devices, some workers have looked at ways of measurement which are minimally invasive. The general aim of this work is to avoid, where possible, the need for traditional blood sampling. Most efforts have targeted methods of drawing fluid through the skin without conventional puncture.

Early work involved abrasion of the skin, but a more recent approach is based on electroosmosis and electrochemical measurement of interstitial fluid. The GlucoWatch ${ }^{\circledR}$ (Cygnus Inc., Redwood City CA, USA) is a wrist-worn device intended for detecting trends and tracking patterns in glucose levels in adults with diabetes. The device is intended for use at home and in healthcare facilities to supplement, not replace, information obtained from standard home blood glucose monitoring devices. Due to the frequency of the automatic and non-invasive measurements, the GlucoWatch ${ }^{\circledR}$ biographer has the potential to provide patients with previously unavailable information about blood glucose, including: automatic and frequent measurements and alerts for high and low glucose levels.

Following a three-hour warm-up period, the device is capable of providing up to three glucose readings per hour for 12 hours after a single point calibration with the results from a standard finger-stick meter. The GlucoWatch ${ }^{\circledR}$ biographer uses reverse iontophoresis to collect glucose samples through intact skin (Figure 20). 


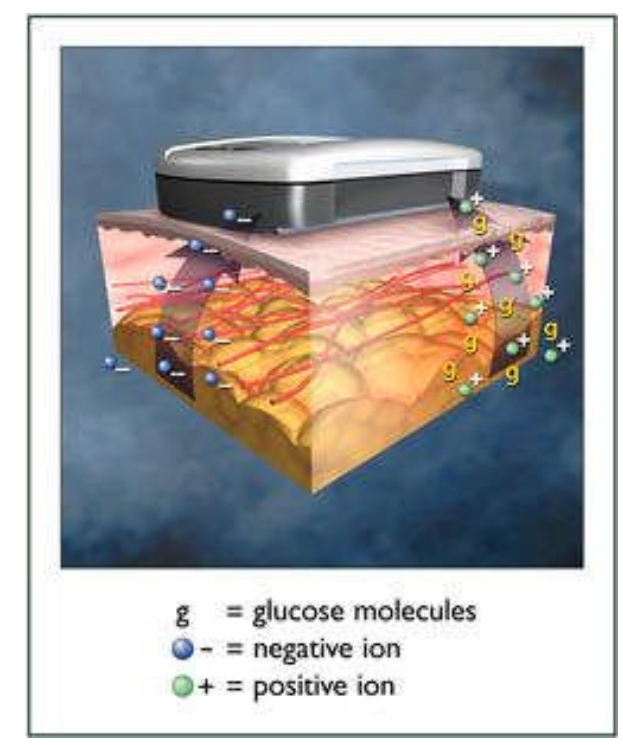

\section{Figure 20: Glucowatch Operating Principle}

The glucose molecules are collected in gel collection discs that are part of a single-use AutoSensor. The gel collection discs contain the enzyme glucose oxidase. As glucose enters the discs, it reacts with the glucose oxidase in the gel to form hydrogen peroxide. A biosensor in contact with each gel collection disc detects the hydrogen peroxide, generating an electronic signal. The biographer uses the calibration value previously entered by the patient to convert the signal into a glucose measurement. The glucose measurement is then displayed on the biographer and stored in memory. In 2001, the GlucoWatch ${ }^{\circledR}$ biographer received approval from the United States Food and Drug Administration (FDA).

Integ (St. Paul, MN, USA) has been developing the LifeGuide ${ }^{\mathrm{TM}}$ hand-held instrument that, when pressed against the skin on the forearm, uses a small needle to collect interstitial fluid, which is then analyzed by infrared spectroscopy. A $1 \mu$ sample of interstitial fluid is collected through a $1.4 \mathrm{~mm}$ hole in the dermis. No blood is drawn, and the method is less painful than with conventional lancets. A recent research study demonstrated that the dermal interstitial fluid results closely tracked blood results. However, initial tests using infrared sensors have not been sufficiently accurate and it is believed that a more conventional approach using glucose oxidase biosensors is being pursued.

The approach proposed by SpectRx ${ }^{\mathrm{TM}}$ (Norcross, Georgia, USA) is to measure glucose levels in interstitial fluid. This is collected through an array of microscopic holes, created with a laser in the stratum corneum, the dead outer layer of skin, and measured in a patch containing a glucose sensor. Interstitial fluid is the clear fluid under the skin through which glucose and other nutrients travel from the blood stream to the cells. Interstitial fluid and blood generally contain very similar glucose concentrations, as long as the blood glucose levels are steady and not rising or falling. The problem with this approach may be when glucose levels are rapidly falling or rising, in which case the interstitial fluid glucose concentration may trail or possibly precede that found in serum or blood. There is therefore a slightly increased risk of hyper- or hypoglycaemia with insufficient warning. 
Bioject Inc. (Portland, Oregon, USA) is best known for its innovative drug delivery systems, based on needle-free injection. The company has been adapting this technology and using it to develop a glucose monitoring system, which will continuously measure glucose levels on a 24-hour basis. The system is a patch-like sensor coupled with a smart card similar in size to a credit card that can be kept the pocket. The sensor and the card are connected by a telemetric system.

An interesting sampling system is being developed by Kumetrix (Union City, CA, USA), based on silicon micro-needles similar in size to a human hair. The aim is to develop a hand-held, battery-powered electronic monitor, which accepts a cartridge loaded with disposable sampling devices. Each disposable consists of the microneedle and a receptacle into which the blood sample is drawn. To take a measurement, the patient will load the cartridge into the electronic monitor and simply press the monitor against the skin. This action will cause the micro-needle (Figure 21) to penetrate the skin and draw a very small volume of blood (less than 100 nanolitres) into the disposable element, where the blood-glucose concentration will be measured.

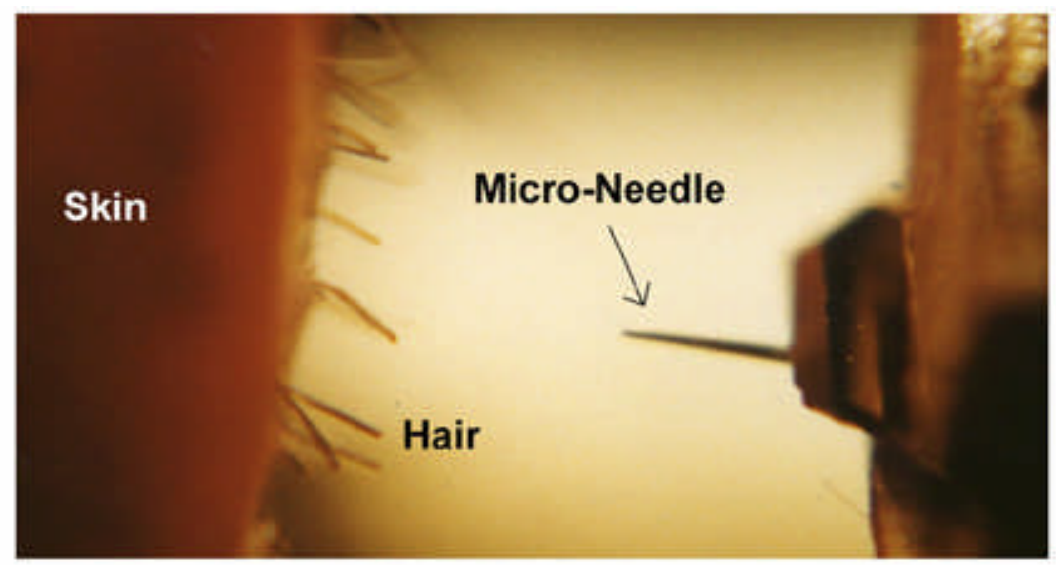

Figure 21: Silicon Micro-Needle

\subsection{Non-Invasive Systems}

There are numerous potential methods for the measurement of glucose noninvasively. These include:

- Direct measurement of interstitial fluid or sweat. This has the potential advantage of using conventional analytical measurement techniques.

- Transcutaneous infrared spectroscopy. Near IR spectroscopy has been used successfully to measure cerebral haemodynamics as the spectral features of haemoglobin and oxyhaemoglobin are strong and different. The same is not the case for glucose, where variations are subtle and not unique.

- Fluorescence lifetime or RF spectroscopy.

- Pulse laser photoacoustic spectroscopy. Instead of measuring transmitted or absorbed light, an optically generated pressure wave is created within the medium and detected at any other point. The pressure and photoacoustic 
spectra are dependent on laser energy, optical absorption coefficient, thermal expansion coefficient, velocity of sound, and specific heat. One can potentially use variations in these parameters with concentration to attempt measurement. This has been demonstrated in preliminary work for glucose.

- Far infrared (FIR) spectroscopy. This technique monitors FIR emitted by the body and thus requires no external energy source. Glucose, for example, absorbs in a band around $9.4 \mathrm{~m}$, but the signal is very small and current detectors require cryogenic cooling.

- Breath analysis could be carried out via gas chromatography-mass spectrometry (GC-MS), of the components in exhaled air.

- Optical analysis through the eye. For example, spectral analysis of the chemical components in vitreous humour.

- Polarimetric techniques. The rotation of linearly polarised light is used to quantify concentrations of a chiral solution. Such an approach has been suggested for glucose determination, but the key problem in vivo is that the skin is highly scattering, which depolarises most of the light. It could be applied through the eye, but problems remain with corneal birefringence, eye motion artifacts, and the time lag between blood and vitreal concentrations.

- Impedance methods. It is possible to analyse the impedance of the skin and underlying tissue non-invasively using contact electrodes. It is claimed that frequency dependent impedance characteristics can be related to the local glucose concentration.

Despite the difficulties involved in using NIR spectroscopy for the measurement of glucose in vivo, the approach has been pursued and some companies have claimed to have overcome the problems. However, the clinical utility of these devices has not been accepted.

Pendragon (Zurich, Switzerland) is developing a non-invasive continuous glucose monitoring system, which uses impedance spectroscopy to measure glucose-related effects. The Pendra ${ }^{\mathrm{TM}}$ measures how changes in blood composition affect the impedance pattern of the skin and underlying tissue. The device itself is the size of a wrist watch (Figure 22) and is fixed with an open resonant circuit which lies against the skin. The device is optimised to measure the indirect affects of glucose molecules on the impedance pattern, these measurements are then calculated into glucose concentrations. The device is claimed to be suiable for use by both Type 1 and Type 2 diabetics. However, as is the case with the Cygnus and Minimed devices, Type 1s must follow a warning from the device with a fingerstick test. Differences in the thickness of skin and underlying tissues of the patient require a two-point calibration process. This provides individual user data about absolute offset and the ratio between impedance changes and glucose changes. Variations on impedance due to temperature changes are self-corrected. 


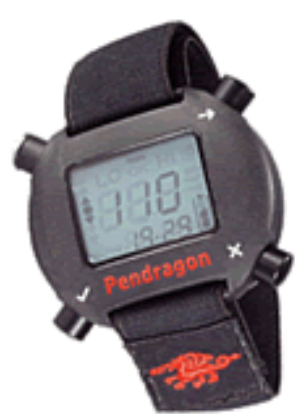

Alpha Series

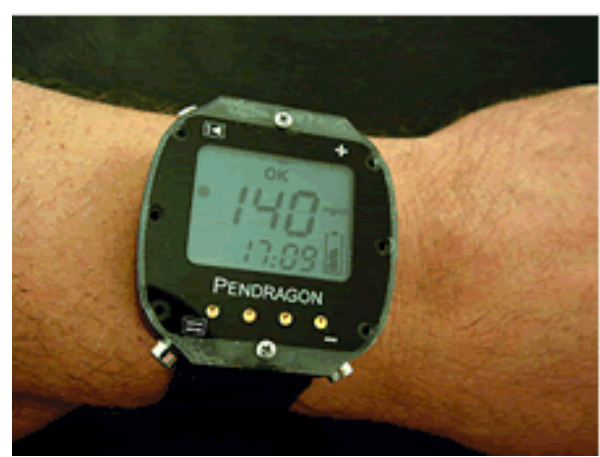

Beta Series

Figure 22: Pendragon Continuous Glucose Monitors

Pendragon's instrument is designed to work in conjunction with an invasive glucose meter in order to track blood sugar readings and detect patterns. It is claimed that the device will provide a continuous non-invasive measurement of glucose levels, as well as a hypoglycaemia alert system. Displaying a glucose value every minute (an average over the last five minutes) with date and time, it also has an upward or downward trend indicator, which alerts when the speed of change is too rapid.

Currently Pendragon is redesigning both the software and hardware for the Alpha series. Further developments also include the coating of the antenna circuit and algorithm improvements, in preparation for further clinical trials and review by regulatory authorities. It is not clear what interference problems this device might encounter and whether or not it will be available in the United States. Other diabetes related products being developed by Pendragon include software management systems for both patient and physicians. On May $12^{\text {th }} 2003$, Pendragon Medical Ltd. received Medical Device Directive CE mark certification for their Pendra ${ }^{\mathrm{TM}}$ brand Glucose Monitor. However, at the time of writing, the product had not reached the marketplace and has faced some serious criticism in the press.

\subsection{Issues Concerning Glucose Biosensors}

Many of the issues associated with glucose biosensors have very little to do with the device itself. In virtually every case, the basic design of the commercially-successful biosensors has not changed significantly for some time. Mediated amperometric designs similar to the original MediSense ExacTech ${ }^{\mathrm{TM}}$ device, which was first launched 15 years ago, are still the norm. Meter companies have been very slow to introduce new technology and have relied on a strategy of putting existing technology in a new box, combined with a marketing campaign targeted at a specific segment of the market. This strategy enables short term maintenance of market share, but does little to expand the market beyond the current installed user base.

Some trends are noticeable. The active area of the biosensor has universally become smaller, enabling lower sample volumes to be analysed. As can be seen in Table 2, sample requirements can be less than a microlitre. Modelling of the response characteristics has also made quicker analyses possible. A result can now be obtained in as little as 5 seconds, although the average test time is a little higher than this. 
Table 2: Characteristics of Leading Commercially-Available Glucose Biosensors

\begin{tabular}{cccccc} 
& $\begin{array}{c}\text { LifeScan } \\
\text { One-Touch } \\
\text { Ultra }\end{array}$ & $\begin{array}{c}\text { Roche } \\
\text { Diagnostics } \\
\text { Accu-Chek } \\
\text { Advantage }\end{array}$ & $\begin{array}{c}\text { Bayer } \\
\text { Diagnostics } \\
\text { Glucometer } \\
\text { Elite XL }\end{array}$ & $\begin{array}{c}\text { TheraSense } \\
\text { FreeStyle }\end{array}$ & $\begin{array}{c}\text { MediSense } \\
\text { Precision } \\
\text { Q.I.D }\end{array}$ \\
\cline { 2 - 6 } $\begin{array}{c}\text { Alternate Site } \\
\text { Testing }\end{array}$ & Yes & No & No & Yes & No \\
$\begin{array}{c}\text { Sample Size }(\mu \mathrm{l}) \\
\text { Test Time (seconds) }\end{array}$ & 1 & $3-4$ & 2 & 0.3 & 3.5 \\
$\begin{array}{c}\text { Test } \\
\text { Capillary Action } \\
\text { Strip }\end{array}$ & 5 & 40 & 30 & 15 & 20 \\
$\begin{array}{c}\text { Temp. Range }\left({ }^{\circ} \mathrm{C}\right) \\
\text { Yes }\end{array}$ & $5-44$ & $8-39$ & $10-39$ & $10-35$ & $18-30$ \\
$\begin{array}{c}\text { Test Memory } \\
\text { Data Downloading }\end{array}$ & 150 & 100 & 120 & 250 & $10-125$ \\
\hline
\end{tabular}

The way in which a sample is obtained is also an issue undergoing considerable research and discussion. As sample sizes have become smaller, questions have been asked about how representative the sample becomes. This is particularly true in the case of the most minimally-invasive of the sampling regimes, which often measure glucose in interstitial fluid.

\subsubsection{Sampling Regimes}

Two trends have emerged in sampling: volume reduction and alternative sites. The latest sensors require very low sample volumes, which has led to a need for sampling systems that can obtain a representative blood sample with the minimal pain inherent with such a sampling regime. It appears that significant efforts will continue to be made in this area in the near future. The following discussion highlights what is under development and suggests which technologies appear to be promising for the future.

Most of the current blood glucose biosensors measure the glucose in a small sample of capillary blood, which is obtained from the finger, using a lancet (Figure 23).

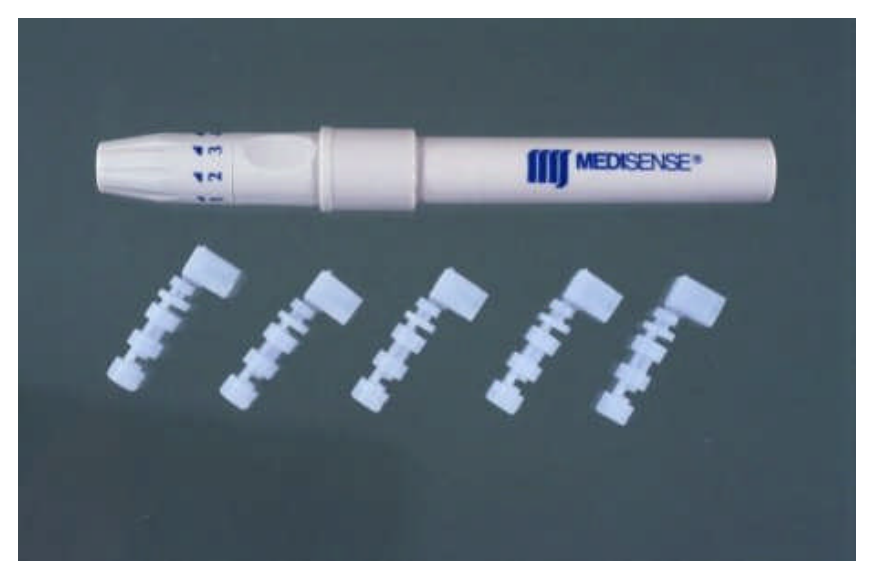

Figure 23: Lancet for Obtaining a Sample of Capillary Blood 
Even though the required samples need be no greater than a microlitre or so, there has been considerable effort aimed at enabling measurements to be made in other media, thus removing the need to draw blood. The process of taking capillary blood is inconvenient and uncomfortable, particularly for young diabetics and parents of diabetic children, who find this particularly stressful.

The Bayer Microlet ${ }^{\circledR}$ Vaculance is suitable for non-finger use. The endcap is removed to insert a lancet and the lancet cap removed. After replacing the endcap, the puncture depth is adjusted by rotating and aligning the transparent endcap to one of four settings. The Vaculance ${ }^{\circledR}$ is pressed against the puncture site and the lancet fired by completely depressing the plunger. An airtight seal is then formed by slowly releasing the plunger which creates a vacuum. This causes the skin to bulge into the endcap, dilating the puncture and increasing the flow of blood (Figure 24). The transparent endcap enables the operator to see when sufficient blood has been collected, at which point the vacuum is released by partially depressing the plunger. If this step is omitted, any residual vacuum creates aerosols.

Blood is then applied to a glucose test strip in the usual way. The used lancet is removed, recapped and discarded. The use of the Vaculance ${ }^{\circledR}$ is limited to glucose measuring systems that aspirate (by capillary draw) small sample volumes of approximately $3 \mu 1$. Bayer designed it for use with the Glucometer Esprit and Elite.

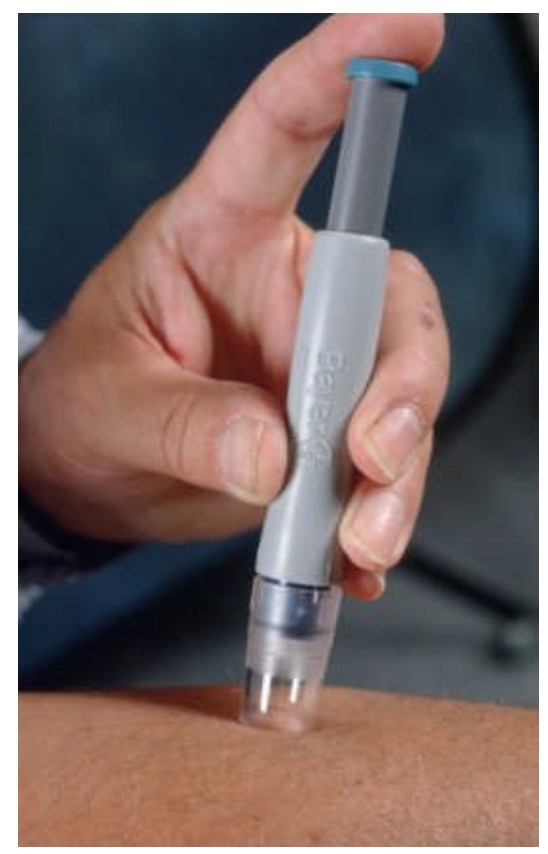

Figure 24: Bayer Microlet ${ }^{\circledR}$ Vaculance

Several methods have been proposed for obtaining small samples of interstitial fluid (ISF) in a painless manner. The most promising (and those with the most commercial backing) involve laser ablation, ultrasound or reverse iontophoresis. 
Laser ablation uses short laser pulses to open up small pores in the epidermis, allowing a small sample of interstitial fluid to be released (Figure 25). The process is painless and causes minimal damage to the skin.

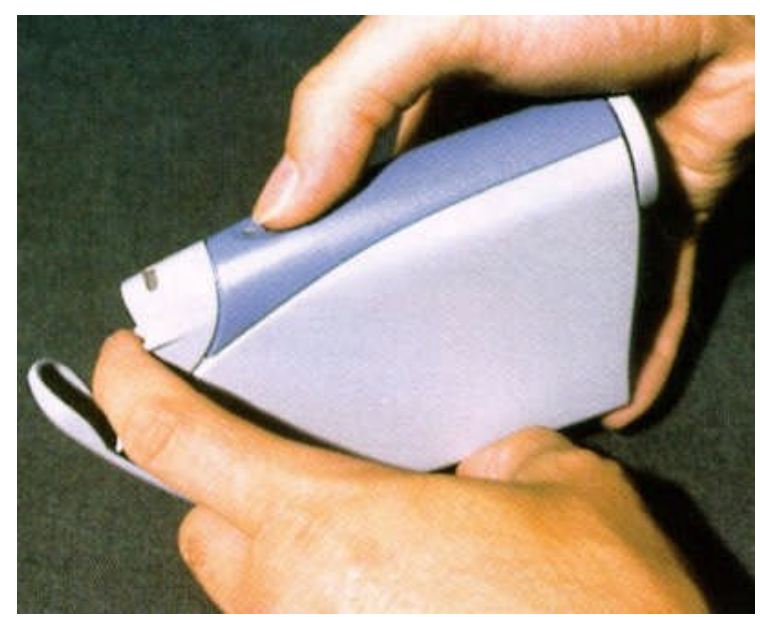

\section{Figure 25: Cell Robotics Lassette® Laser Ablation Blood Sampling Device}

Ultrasound can also be used to open pores in the skin. The original application of this technology was envisaged to be opening pores to allow drug administration, but it has been demonstrated for diagnostic applications by Sontra Medical (Cambridge MA, USA), who have used the technology to open pores to extract a sample.

Reverse iontophoresis relies on glucose being carried in an ion flow induced by electrolyis (Figure 20). The flow of (mainly sodium and potassium) ions carries glucose to the surface of the skin, where it can be measured. Unfortunately, the Glucowatch, which utilises this principle, is neither simple to use, nor painless. However, the success of such a device would, undoubtedly, change the balance of power in the meter market.

There is, however, some controversy about the validity of measurements made in interstitial fluid (ISF). This is located in the outermost layers of the skin, above the nerve endings. Hence, withdrawal of ISF from the interstitial space above the nerve endings draws no blood and, according to the manufacturers, causes little or no pain. Some research studies conclude that ISF glucose measurements are accurate for diabetes glucose testing, but others say this has not been completely proven and more research is necessary. The prinicpal problem is the delay before changes in blood glucose are reflected in ISF, which means that the correlation between ISF and blood can be good as long as the blood glucose levels are steady and not rising or falling. If the blood levels are rapidly changing, then ISF glucose levels may trail or possibly precede serum glucose levels. If this lag time is found to be significant, diabetic patients are at an increased risk of becoming hyper- or hypoglycemic without adequate warning. Companies who use ISF measurements claim that clinical studies have shown that this lag time either does not exist, or that it is rarely more than about five minutes, or so, and is insignificant. 
The first alternative site system to receive FDA approval was Amira's AtLast ${ }^{\mathrm{TM}}$ Blood Glucose System. Significantly, it measures blood, rather than ISF glucose. The measurement sites are on the forearm or thigh, which have a lower density of nerve endings than the fingertips. The success of this technology prompted the acquisition of the company by Roche Diagnostics in November 2001. Other similar devices have followed from several of the other major manufacturers.

The fact that ISF measuring products have been slow to get approval is indicative of the problems that interstitial fluid presents. Nevertheless, the area is being heavily pursued and, despite its problems, the Cygnus Glucowatch has reached the marketplace.

It has also been suggested for some time that it may be possible to measure glucose in saliva, urine or teardrops. There is some evidence that these are possible alternatives and that correlations with blood glucose levels can be established. However, the issue of a lag time between glucose concentrations in these media and those of blood is even more of a problem in each of these cases.

\subsubsection{Plasma Calibration}

There is a definite trend in the newest blood glucose meters and test strips towards plasma calibration. All of the current meters take a whole-blood sample to calculate blood glucose concentration, but many of the newer devices have been calibrated to provide the result as a plasma equivalent. Despite the possible confusion that this procedure could be seen to provoke, it is being implemented to make results compatible with laboratory tests, which are usually expressed in plasma values.

Plasma-calibrated meters make it simpler for medical staff to compare the results obtained from a meter with results from the laboratory. Typically, a plasma-calibrated meter will report a reading which is approximately 8 to $12 \%$ higher than that obtained with a whole-blood calibrated meter at a haematocrit level of about $43 \%$.

There is little evidence that one leading model or brand is noticeably less accurate than any other. However, older meters tend to be less accurate, leading some physcians to recommend to their patients to change their meter regularly since, with a trade in, the cost of this is usually little or nothing.

\subsubsection{Integrated Sensor-Sampling Systems}

One of the drawbacks of current blood glucose monitors is that users have to carry around the lancing device, a supply of lances, biosensor strips, the meter and case. They then have to manually manipulate these components, often four or more times a day, 365 days a year. Many patients even resort to having multiple meters, for use at home, in the car, in the office, on the golf course and so on. Several manufacturers have partially addressed this problem. The Roche Compact ${ }^{\mathrm{TM}}$, for example, has 17 test strips contained within a cartridge.

An all in one device, containing 50 self-calibrating test strips, a lancing device and meter, all in a single unit, roughly the size of a pager would be a leap forward in convenience. Pelikan Technologies Inc. (Palo Alto, CA, USA) has already received 
FDA approval (in April 2003) for an advanced lancing device called the Pelikan Sun $^{\mathrm{TM}}$ (Figure 26). This lancing device is a proprietary fully automated, self-contained system and is the first such product to be electronically controlled. It thus provides superior convenience and significantly reduced pain to people with diabetes, as compared to currently marketed lancing devices.

Based on a "one-step, one-button" approach, the device is the first system that allows a patient to execute the entire lancing process at the touch of a button. The unit utilises Smart Lancing ${ }^{\mathrm{TM}}$ technology, which provides smooth and highly electromagneticallycontrolled lancing at the lowest useful penetration depth, which eliminates much of the pain. A specially designed self-contained lancet disk eliminates the need to handle sharps, whether the sharp lancets are new or contaminated. The disk, which contains 50 sterile lancets, is simply replaced after 50 uses. Individuals with diabetes, most importantly children, will not have to see or handle a lancet ever again. The Pelikan Sun was first exhibited publicly at the 63rd American Diabetes Association Scientific Sessions in June 2003 and is expected to be commercially available in 2005.

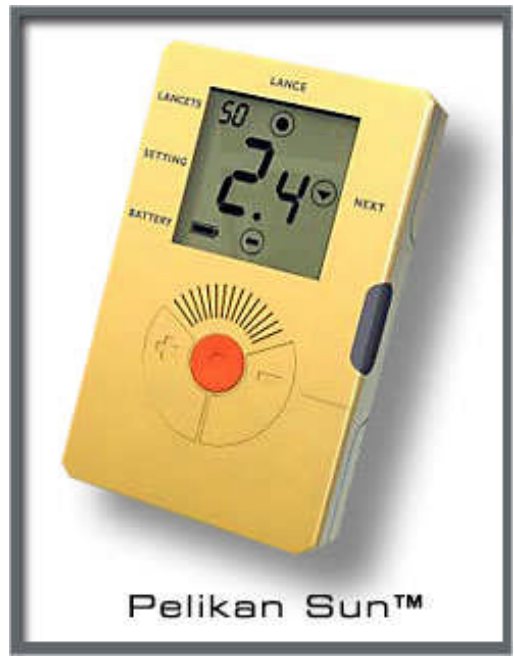

Figure 26: Pelikan Sun ${ }^{\mathrm{TM}}$ Lancing Device

As good as this device may be, it is only the first stage in Pelikan's development portfolio, since, on its own, it is of limited commercial value. To quote David Kliff, of the Diabetic Investor:

"The Sun is a nice little device, but Diabetic Investor sees little commercial value in a lancing device alone, even if it is less painful than conventional lancing devices. We've been down this road before with the Lassette by Cell Robotics. Quite frankly, users are unwilling to pay for a device when they get a lancing device for free with any new meter. Pain may be an issue, but not as big an issue as one's pocketbook. However, add in a meter to the Sun, and now you have something unique."

Pelikan is developing next-generation diagnostic and monitoring devices that will provide additional benefits to individuals with diabetes. The company's secondgeneration product is a one-step, fully integrated blood glucose sampling and measurement solution. The electrochemical measurement technology and 
microfluidics combine to provide more accurate results on a sample as small as $200 \mathrm{nl}$. The result will be a convenient device that will significantly reduce pain and eliminate daily medical waste. Pelikan intends to launch this all-in-one device in early 2006.

Integrated technologies are also being developed by Roche Diagnostics. The 'continuous strip' is claimed to be a breakthrough technology enabling many tests to be performed on a single strip. The second integrated device in development combines a lancet and measuring needle and is designed to improve patient comfort.

\subsubsection{Developments in Non-Invasive Glucose Sensors}

With all of the above techniques, relatively conventional measurement technologies can be applied. Other principles are under development, however, which rely on completely different approaches. It has long been suggested that it would be possible to measure blood glucose in a similar way to which blood oxygen can be measured using near infra red light spectroscopy. This approach was most notably pursued by Futrex, for example in the early 1990s.

Unfortunately, the glucose spectrum in this light region is diffuse and complex and in a region plagued by interference, making analysis difficult. Nevertheless, the approach has attracted a lot of interest, primarily because of the opportunities presented. The method would allow continuous measurement if necessary and would be completely painless. Optical coherence tomography (OCT) is another technique that has emerged as a candidate non-invasive approach. OCT is a novel biomedical imaging technique with very high spatial resolution. It relies on the wave nature of the light, and on the coherence properties of lasers, to generate micron-scale cross sectional subsurface images of tissue. OCT is similar to ultrasound, except reflections of near-infrared light, and not sound echoes, are used to produce 2-D or a-D images of tissue microstructure, which have been shown to correlate with glucose concentration. Initial studies, involving skin measurement look promising, but much further work is needed.

The measurement site itself has attracted a considerable amount of attention. Some of the proposed sites have included the finger, the arm and the earlobe. Unfortunately, the problems encountered have been the same for virtually all of these sites, since the measurement matrix in each of these is extremely heterogeneous.

One possible way of making an optical measurement, which is less problematic, is to look at the back of the eye, using a reflectance technique. The matrix in this case is much simpler and homogeneous, and the rear of the eye has a blood supply close to its inner surface (Jang \& Fox, 1998).

\subsection{Fabrication Issues}

The ability to produce devices in large numbers and at a low cost is certainly a major requirement for many biosensors, particularly those aimed at self-testing markets, where one-shot use has many advantages (not least commercially in terms of continued after-sales!). It is also true that the ability to produce better defined and smaller structures will open up new possibilities. This section looks at the advances 
already underway and the obstacles that need to be overcome and then examines some of the opportunities available.

\subsubsection{Screen-Printing Advances}

As was discussed earlier, screen-printing has had a huge impact on the commercialisation of biosensors. Many of the most successful electrochemicallybased devices to date have used the technique. Typical production screen-printers are shown in Figure 27.

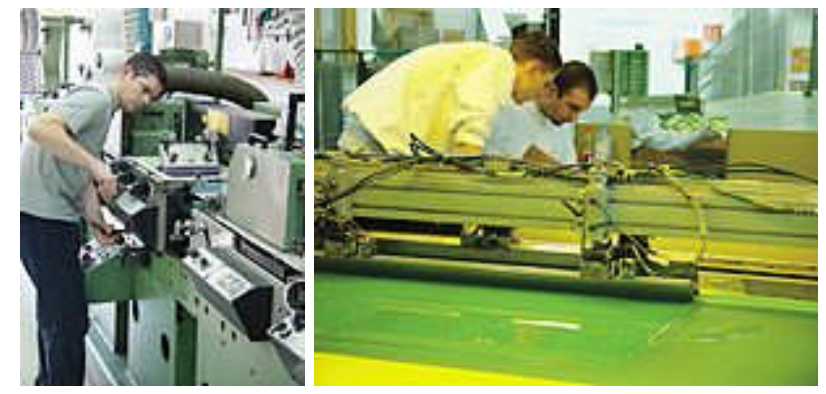

Figure 27: Production Scale Screen-Printers

However, the full commercial impact of the technology has been somewhat limited by the range of inks available for the construction of inexpensive devices. Amongst others, Gwent Electronic Materials (Pontypool, Gwent, UK) is developing a new range of low fire materials. Using a new technology, the firing temperature of metallic-based pastes has been reduced from the normal temperatures of $400-450^{\circ} \mathrm{C}$ to the range of $150-350^{\circ} \mathrm{C}$. This type of system means that it is now possible to fire onto polymeric rather than ceramic materials. Additionally, they have found that it is possible to produce a precious metal coating which is able to connect directly to base metal systems at a temperature below which oxidation would normally be a problem. These modifications to the metallic film give the ability to render the surface easily solderable. It is expected that these developments will open up new opportunities for inexpensive, precious metal-based chemical sensors and biosensors.

As a result of the intensive research and expertise acquired in this area, Palintest (Tyne and Wear, UK) has developed screen-printed sensors for the detection of lead, cadmium and copper. These devices contain no biological components, but it is an interesting spin-off from what was, originally, a technology developed for biosensors.

\section{Conclusions and Future Prospects}

In the absence of a cure for diabetes, home blood glucose monitoring will undoubtedly need to continue and the current commercial dominance of mediated electrochemical biosensors will not be easily displaced. While the frequency of testing has faltered in some established markets, new geographical areas are opening up and manufacturers are engaged in fierce competition to maintain and expand market share. New technology has largely arisen in universities and small innovative companies and has then been acquired by the major players who have the distribution 
networks and market muscle to do justice to new inventions. Investment continues in non-invasive technology, but products to date have disappointed the market and led to a lack of credibility. In vivo monitoring has materialised after a long gestation period, but utility is still somewhat limited. Companies appear to have reached a consensus, as evidenced by their recent product introductions and publically announced research programmes, that the most important next range of home blood glucose monitoring products will be integrated devices. Integration will take several forms and include instruments offering multiple glucose tests, multiple analytes, lancing combined with testing, testing combined with injectors and pumps combined with sensors. The most successful formats will address real needs, sizeable patient groups and offer unrivalled convenience in simplicity of operation and portability.

\section{References}

Albers, M.W., Lekkala, J.O., Jeuken, L., Canters, G.W. \& Turner, A.P.F. (1997). Design of novel molecular wires for realizing long distance electron transfer. Bioelectrochem. Bioeng., 42, 25-33.

American Diabetes Association (1994). Self-monitoring of blood glucose. Diabetes Care, 17, 81-86.

American Diabetes Association (2004). National Diabetes Fact Sheet. http://www.diabetes.org/diabetes-statistics/national-diabetes-fact-sheet.jsp

Cass, A.E.G., Francis, D.G., Hill, H.A.O., Aston, W.J., Higgins, I.J., Plotkin, E.V., Scott, L.D.L. \& Turner, A.P.F. (1984). Ferrocene-mediated enzyme electrode for the amperometric determination of glucose. Anal. Chem., 56, 667-671.

Clark, L.C. (1956). Monitor and control of blood and tissue oxygen tensions. Trans. Am. Soc. Artif. Intern. Organs, 2, 41-48.

Clark, L.C. \& Lyons, C. (1962). Electrode systems for continuous monitoring in cardiovascular surgery. Ann. NY Acad. Sci., 102, 29-45.

Clemens, A.H. (1971). Reflectance meter. US Pat. No. 3604815, 14 September 1971.

Jang, S. \& Fox, M.D. (1998). Optical sensor using the magnetic optical rotatory effect of glucose. www.ieee.org/organizations/pubs/newsletters/leos/apr98/ opticalsensor.

Katz, E. \& Willner, I. (2001). Biomolecular Architecture: Routes to Biosensors, Bioelectronics and Biofuel Cells. Proc. First International Symposium on Macro- and Supramolecular Architectures and Materials (MAM-01): Biological and Synthetic Systems, Kwangju, South Korea, 10-14 April, 2001

Newman, J.D., White, S.F., Tothill, I.E. \& Turner, A.P.F. (1995). Catalytic materials, membranes and fabrication processes suitable for the construction of amperometric biosensors. Anal. Chem., 67 (24), 4594-4599. 
Newman, J.D., Warner, P.J., Turner, A.P.F. \& Tigwell, L.J. (2004). Biosensors: A Clearer View. Cranfield University, UK, 216pp.

Schultz, J.S. (1982). Optical sensor for plasma constituents. US Patent No. 4344438.

Shichiri, M., Kawamori, R., Yamaski, R., Hakai, Y. and Abe, H. (1982). Wearable artificial endocrine pancreas with needle-type glucose biosensor. Lancet ii, 11291131.

Turner, A.P.F. and Swain, A. (1988). Commercial perspectives for diagnostics using biosensor technologies. American Biotechnology Laboratory, November, 10-18.

Vijayakumar, A.R., Csoregi, E., Heller, A. \& Gorton, L. (1996). Alcohol biosensors based on coupled oxidase-peroxidase systems. Anal. Chim. Acta., 327 (3), 223-234.

WHO (2004). Diabetes action now: an initiative of the World Health Organisation and the International Diabetes Federation. WHO, Geneva, Switzerland, ISBN 924159151 $\mathrm{X}$.

Zhang, X-E. (2004). Screen-printing methods for biosensor production. In Biosensors: A Practical Approach, ed. J.M. Cooper \& A.E.G. Cass, $2^{\text {nd }}$ Edition, Oxford University Press, New York, 41-58. 